Canadian

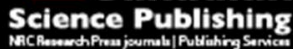

Canadian Geotechnical Journal Revue canadienne de géotechnique

\title{
Influence of Strain Energy Released from a Test Machine on Rock Failure Process
}

\begin{tabular}{|r|l|}
\hline Journal: & Canadian Geotechnical Journal \\
\hline Manuscript ID & cgj-2017-0256 \\
\hline Manuscript Type: & Article \\
\hline Date Submitted by the Author: & $05-$ May-2017 \\
\hline $\begin{array}{r}\text { Complete List of Authors: } \\
\text { Is the invited manuscript for } \\
\text { consideration in a Special } \\
\text { Issue? : }\end{array}$ & $\begin{array}{l}\text { Nu, Yuhang; Laurentian University Faculty of Science and Engineering, } \\
\text { Cai, Ming; Laurentian University, }\end{array}$ \\
\hline Keyword: & $\begin{array}{l}\text { Loading system stiffness, stiff test machines, energy transfer, strain } \\
\text { energy, rock failure process }\end{array}$ \\
\hline
\end{tabular}

\section{SCHOLARONE ${ }^{\text {m }}$ \\ Manuscripts}




\title{
Influence of Strain Energy Released from a Test
}

\section{Machine on Rock Failure Process}

\author{
Y.H. $\mathrm{Xu}^{1,2}, \mathrm{M} . \mathrm{Cai}^{1,2,3}$ *
}

1. Bharti School of Engineering, Laurentian University, Sudbury, Ont., Canada P3E 2C6

2. MIRARCO, Laurentian University, Sudbury, Ont., Canada P3E 2C6

3. Key Laboratory of Ministry of Education for Safe Mining of Deep Metal Mines, Northeastern University, Shenyang 110004, China)

(*Corresponding author: Ming Cai (mcai@laurentian.ca))

\section{Abstract}

Rock instability occurs if the energy supplied to the rock failure process is excess. The theoretical analysis on the energy transfer in rock failure process revealed that the rock failure process is a result of the strain energy released from the test machine or the surrounding rock masses of wall rock, plus the additional energy input from an external energy source if the deformation of the rock is continued and driven by the external energy source. The strain energy released from the test machine is focused in this study because it is responsible for some of the unstable rock failures in laboratory testing. A FEM-based numerical experiment was carried out to study the strain energy released from test machines under different loading conditions of $L S S$. The modeling results demonstrated that depending on the LSS of a test machine, the strain energy 
released from the test machine alone without additional energy supply can drastically affect the rock failure process. The insight gained from this study can explain unstable rock failure in laboratory tests and the mechanism of some delayed rockbursts that occurred some time after the excavation of the openings.

Keywords: Loading system stiffness; stiff test machines; energy transfer; strain energy; rock failure process

\section{List of symbols}

$\begin{array}{ll}A & \text { Cross-sectional area } \\ \delta & \text { Displacement } \\ E_{\text {in }} & \text { Accumulative energy input from an external energy source at peak load } \\ E_{\mathrm{r}} & \text { Accumulative energy consumed in a rock specimen at peak load } \\ E_{\mathrm{t}} & \text { Strain energy stored in a test machine at peak load } \\ E_{\mathrm{in}}{ }^{*} & \begin{array}{l}\text { Accumulative energy input from an external energy source at post-peak deformation } \\ \text { stage }\end{array} \\ E_{\mathrm{r}}^{*} & \text { Accumulative energy consumed in a rock specimen at post-peak deformation stage } \\ E_{\mathrm{t}}{ }^{*} & \text { Strain energy stored in a test machine at post-peak deformation stage } \\ \Delta E_{\mathrm{in}} & \text { Energy input from an external energy source during post-peak deformation stage } \\ \Delta E_{\mathrm{r}} & \text { Energy consumed in a rock specimen during post-peak deformation stage } \\ \Delta E_{\mathrm{t}} & \text { Strain energy released from a test machine during post-peak deformation stage } \\ \Delta E_{\mathrm{r}} \mathrm{B} & \text { Energy item } \Delta E_{\mathrm{r}} \text { under the ideal loading condition } \\ E_{\mathrm{p}} & \text { Post-peak stiffness of a rock specimen in stress-strain curve } \\ H & \text { Height of a column-shaped structure } \\ k & \text { Longitudinal stiffness of a column-shaped structure } \\ \lambda & \text { Post-peak stiffness of a rock specimen (absolute value) }\end{array}$




\section{Introduction}

Pioneer works on rock failure process were conducted by Griggs (1936), Kiendl and Maldari (1938), and Handin (1953) in the 1930s and 1950s. The subject of rock mechanics as an independent engineering discipline started in the 1960s, when the development of test machines permitted the study of rock deformation behavior (Ulusay 2015). According to Goodman (1989), a test machine is a reaction frame in which a screw or a fluid loading ram is operated to load a specimen. In 1965, Cook (1965) explained the possibility of observing the post-peak deformation behavior of rock by increasing the loading system stiffness (LSS) of a test machine.

The post-peak deformation behavior of rock is useful in predicting the extent of excavation damaged zones (Alonso et al. 2003; Bieniawski 1967; Cai et al. 2007b) and the duration of rock failure as a result of rock creep (refer to discussion in Section of indirect observations on the strain energy released from test machines or surrounding rock masses and its impact on rock stability). Moreover, the post-peak deformation behavior is important to determine the likelihood of rock instability (refer to discussion in Section of stable rock failure criterion and energy transfer in rock failure process). Before 1966, observations on the loaddeformation relation of rock were limited in the pre-peak deformation stage because the rock failure process was unstable immediately after the maximum load-carrying capacity of rock had been reached, largely due to low $L S S$ of the test machine relative to the post-peak stiffness of the rock and the inability to extract energy from the loading system quickly as we know it today (Salamon 1970).

\section{Rock laboratory test machines with high LSS}


The first set of complete load-deformation curves of rock were obtained by Cook and Hojem (1966) and Bieniawski (1966) with the aid of stiff test machines. Since then, these precursors, along with others (Cook and Hojem 1971; Stavrogin and Tarasov 2001; Wawersik and Fairhurst 1970), had devoted great efforts to developing test machines with high LSS to ensure that the post-peak deformation behavior of rock can be obtained. A traditional stiff test machine illustrated in Figure 1 normally consists of a steel frame that accommodates the rock specimen inside, end platens contacting the specimen to distribute load, and a fluid loading ram to deform the specimen. Therefore, LSS of a test machine is largely governed by the deformation characteristics of these three loading components. According to Stavrogin and Tarasov (2001) and Hudson et al. (1972), one technique to stiffen a test machine is to add stiff components (e.g., steel columns) parallel to the rock specimen; another is to employ a fluid loading ram with a large cross-sectional area and a small height.

\section{Figure 1 Schematic of a traditional stiff test machine for observing complete stress-strain curves of rock.}

On the basis of traditional stiff test machines, other types of stiff test machines were developed, with a focus on increasing $L S S$ by alleviating the reduction of $L S S$ due to the fluid loading ram. Bieniawski et al. (1969) designed a novel stiff test machine whose fluid loading ram was separated from the rock specimen-loading frame system so that the compressibility of the fluid (e.g., oil) would not affect LSS. Similar to the rationale of the test machine developed by Bieniawski et al. (1969), Stavrogin and Tarasov (2001) developed a stiff test machine whose fluid loading ram was aligned perpendicularly to the loading direction of the specimen. In this fashion, the strain energy released from a pressurised fluid loading ram to a failing specimen was reduced. In particular, the ground-breaking work of Fairhurst and his colleagues on developing 
servo-controlled test machines (Hudson et al. 1971; Hudson et al. 1972; Rummel and Fairhurst 1970) paved the way for observing rock behaviors under more versatile loading conditions. The response time of a servo-controlled test machine was very fast so that fluid could be quickly pumped out from the ram to inhibit violent rock failure. As will be further explained in Section of modeling results and discussions, this is equivalent to extracting energy from an external loading source, which is important to ensure stable rock failure even if the LSS is not very high.

Note that the stiff test machines exemplified above made improvements on increasing their $L S S$, but that did not necessarily make them very different from the traditional stiff test machine (Figure 1). LSS of stiff test machines used in rock laboratory testing is still determined by the stiffness of their key loading components. The loading frame has a large contribution to $L S S$, thus its stiffness is often referred to LSS in manufacturer's specifications (MTS 2013). The loading frame generally consists of a set of parallel steel columns, and the stiffness of which can be readily calculated. Loading platens also affect LSS. However, the deformation of loading platens is complicated by the combination of bending and indentation effects (Bobet 2001). Furthermore, affected by the compressibility of fluid, the dilation of containing vessels and pipes, the incompatible deformation of seal, and the deflection of ram (Bieniawski et al. 1969; Snowdon et al. 1983; Zipf 1992), the stiffness of the fluid in compression is even more complex and it affects $L S S$ as well. Because of the complex boundary conditions and the interaction between different loading components of a test machine, Hudson et al. (1972) suggested using numerical modeling to evaluate the influence of $L S S$ on rock deformation behaviors.

\section{Indirect observations on the strain energy released from test machines or surrounding rock masses and its impact on rock stability}


$L S S$ of test machines nowadays can be made relatively high; however, it is still finite and the test machine can store strain energy in the pre-peak deformation stage of rock and release the energy in the post-peak deformation stage. Therefore, it was speculated in laboratory testing that violent rock failures observed during testing hard rocks could be primarily attributed to the sudden release of strain energy from the test machines (He et al. 2012; Zhao and Cai 2014), rather than to the unceasing displacement of the loading ram when the servo-controlled loading method was employed (Rummel and Fairhurst 1970). Apparently in reality, it is difficult to shut down the energy supply of a test machine to the loading ram fast enough during the process of unstable rock failure, as a means of confirming that it is the strain energy released from the test machine that primarily contributes to unstable rock failure.

In underground engineering, rockburst hazards are prevalent when excavations are excavated in deep ground where in situ stresses are high (Blake and Hedley 2003; Heal 2010; Martin and Maybee 2000; Poplawski 1997; Wu and Zhang 1997). Sometimes, rock instability occurs even during the cease of excavation. For instance, it was found that pillar bursts occurred after blasting in some deep gold mines in South Africa (Malan 1999). Some extremely intense rockbursts occurred when actually there were no excavation activities at the tunnel face at Jinping II hydropower station in China (Li et al. 2012; Zhang et al. 2012). For instance, 38 delayed rockbursts were recorded and the longest delayed rockburst was recorded $163 \mathrm{~d}$ after the excavation (Chen et al. 2012). Therefore, it is inferred that delayed rockbursts could be induced by the strain energy released from the surrounding rock masses, under a condition of relatively low LMS (local mine stiffness) of the surrounding rock masses and high post-peak stiffness of the wall rock. 
Figure 2 presents an explanation basing on the creep behavior of rock (Shao et al. 2006) and the rock instability criterion to account for a type of delayed rockburst. It is illustrated that the strain energy released from the rock surrounding an opening can be the culprit for some delayed rockbursts if rock creep is involved. The locus of rock creep in the load-deformation space is a horizontal line (represented by black dash lines). In situ rock stability is largely dependent upon the relation between the stiffness of surrounding rock masses (i.e., $L M S$ ) and the post-peak stiffness of the rock being overlaid $(\Lambda)$ at the accumulated displacements in its loaddeformation curve (refer to the discussion of rock instability criterion in Section of stable rock failure criterion and energy transfer in rock failure process).

\section{Figure 2 An explanation for the relation between rock creep and delayed rockburst in load-deformation curve.}

For a rock that exhibits constant creep behavior (Shao et al. 2003), the initial load applied to the rock is at the strain level of Point "a." Creep starts at Point "a" and terminates at strain level of Point "b" in its load-deformation curve. $L M S$ is greater than the post-peak stiffness of the rock at this strain level $\left(\Lambda_{b}\right)$; rock instability will not occur because there is an energy deficit inhibiting the strain energy released from the surrounding rock masses to further deform the rock $\left(L M S>\Lambda_{b}\right)$. However, if the initial load is kept constant at the strain level of Point "c", even if it takes a relatively long time for the creep curve to intersect the load-deformation curve at Point "d", rock instability can occur because the energy surplus due to the release of strain energy from the surrounding rock masses is high enough to crush the rock $\left(L M S<\Lambda_{b}\right)$.

However, it is hard to confirm if the delayed rockbursts, such as those observed at Jinping II hydropower station, were resulted from the strain energy released from the surrounding rock masses due to the difficulty of measuring $L M S$ (Brady and Brown 2013). It is 
also difficult to measure the post-peak deformation behavior of rock in the field because of high experimental costs, rigorous site requirements, and complicated preparatory work. In this study, it is planned to carry out a numerical experiment (Jing 2003; Tang et al. 1998) to elaborate how the strain energy released from a test machine can affect the rock failure process at laboratory scale and induce instability. Modeling results from this study can shed light on why rockbursts do not always occur as soon as an opening is excavated.

\section{Theoretical analysis of the energy transfer in rock failure process}

In this section, energy transfer in the rock failure process is analyzed using a theoretical approach. This explains why it is important to investigate the relation between the strain energy released from a test machine or surrounding rock masses and rock instability, which leads to studying the influence of strain energy released from a test machine on rock failure process using the numerical experiment approach.

\section{Stable rock failure criterion and energy transfer in rock failure process}

Rock failure process must be stable to obtain the complete load-deformation curve. LSS was found important in determining whether the rock failure process in laboratory testing is stable or not (Cook 1965; Salamon 1970). The stiffness of an elastic structure is defined as the force per unit deformation required to deform the structure in a particular direction. Thus, the unit of stiffness is $\mathrm{N} / \mathrm{m}$ for load-deformation relation; the unit of stiffness is $\mathrm{N} / \mathrm{m}^{2}$ or Pa for stress-strain relation. For a column-shaped elastic structure under axial loading (Baumgart 2000; Chen and Han 2007), its longitudinal stiffness $(k)$ is determined by its cross-sectional area $(A)$, Young's modulus $(E)$, and height $(H)$ as: 


$$
k=\frac{A E}{H}
$$

Hudson et al. (1972) provided Eq. (2) to calculate the LSS of a test machine:

$$
L S S=\left[\sum_{i=1}^{N} \frac{1}{k_{i}}\right]^{-1}
$$

where $k_{\mathrm{i}}$ is the stiffness of each loading component. According to this equation, the existence of any elastic loading component in a test machine reduces $L S S$, which makes $L S S$ always lower than the stiffness of any single loading component $\left(k_{\mathrm{i}}\right)$. Thus, to increase $L S S$, it is important to decrease the number of loading components and to increase their stiffness.

Salamon (1970) summarized some laboratory test results of rock in compression and reasoned that unstable rock failure would not occur if the test machine was unable to introduce further deformation of rock without the supplement of additional energy from an external energy source once the maximum load-carrying capacity of the rock had been reached. The stable rock failure criterion is formulated as (Salamon 1970):

$$
L S S>\lambda
$$

where $\lambda$ is the steepest post-peak stiffness of the rock specimen and it is proportional to the steepest descending slope of the rock specimen's load-deformation curve ${ }^{1}$. Salamon (1970) further concluded that the criterion to determine the rock instability in situ is:

$$
L M S>\Lambda
$$

where $\Lambda$ is the steepest post-peak stiffness of in situ failing rock, and $L M S$ is the local mine stiffness of the rock masses surrounding the failing rock.

\footnotetext{
${ }^{1}$ The post-peak load-deformation curves of rock are assumed negative in this study. For simplicity, only the absolute values of the post-peak stiffness are compared.
} 
Figure 3 illustrates the energy consumed in a rock specimen $\left(E_{\mathrm{r}}\right)$ and the strain energy stored in a test machine $\left(E_{\mathrm{t}}\right)$ up to the peak load, where the test machine is represented by a spring and energy input $\left(E_{\text {in }}\right)$ from an external energy source is supplied to the rock specimentest machine system to deform the rock. As the load is increased to the peak load, both the strain energy stored in the test machine and the energy consumed in the rock specimen increase, and the energy conservation equation of the system at the peak load is:

$$
E_{\text {in }}=E_{\mathrm{t}}+E_{\mathrm{r}}
$$

\section{Figure 3 Energy transfer in rock specimen-test machine system with the supplement of external input energy.}

At the post-peak deformation stage, Eq. (5) still holds true for the system and asterisk (*) is used to differentiate the energy items at the post-peak deformation stage from those at the peak load. The energy conservation equation of the system at the post-peak deformation stage is:

$$
E_{\mathrm{in}}^{*}=E_{\mathrm{t}} *+E_{\mathrm{r}} *
$$

During the rock failure process, part of the energy stored in the test machine $\left(\Delta E_{\mathrm{t}}\right)$ is released to the rock due to the unloading of the test machine $\left(E_{\mathrm{t}}>E_{\mathrm{t}}^{*}\right)$; thus, $E_{\mathrm{r}}<E_{\mathrm{r}}^{*}$ and $\Delta E_{\mathrm{t}}=$ $E_{\mathrm{t}}-E_{\mathrm{t}}{ }^{*}$. Meanwhile, according the stable rock failure criterion, additional input energy $\left(\Delta E_{\mathrm{in}}\right)$ is required when the rock failure is stable $\left(E_{\mathrm{in}}<E_{\mathrm{in}}{ }^{*}\right)$ because $\Delta E_{\mathrm{t}}$ alone is not sufficient to drive the deformation of the rock in the post-peak deformation stage $\left(\Delta E_{\mathrm{in}}=E_{\mathrm{in}}{ }^{*}-E_{\mathrm{in}}\right)$. Therefore, Eq. (6) for the system during the unloading of the test machine while $\Delta E_{\text {in }}$ is supplied can be expressed in an incremental form as:

$$
E_{\text {in }}+\Delta E_{\text {in }}=\left(E_{\mathrm{t}}-\Delta E_{\mathrm{t}}\right)+\left(E_{\mathrm{r}}+\Delta E_{\mathrm{t}}+\Delta E_{\text {in }}\right)
$$


Accordingly, compared Eq. (7) with Eq. (6), the energy consumed in the rock in the post-peak deformation stage $\left(\Delta E_{\mathrm{r}}=E_{\mathrm{r}}^{*}-E_{\mathrm{r}}\right)$ is composed of two energy items:

$$
\Delta E_{\mathrm{r}}=\Delta E_{\mathrm{t}}+\Delta E_{\mathrm{in}}
$$

Note that the energy transfer in the rock specimen-test machine system during the rock failure process discussed in this and the following sections can be readily applied to the energy transfer of rock failure process in the field. In such a case, the strain energy released from a test machine is comparable to that from the surrounding rock masses in situ.

\section{Energy transfer under unstable loading condition (LSS < $\lambda)$}

Rock failure under the loading condition of $L S S<\lambda$ is unstable. Figure 4 illustrates the energy transfer in the rock specimen-test machine system during the rock failure process when $L S S<\lambda$. The rock behavior under an ideal loading condition of $L S S$ (i.e., $L S S=\infty$ and the rock behavior is free from the influence of $L S S$ ) is simplified by red solid lines, and we call it the base case as opposed to the rock behavior under the loading condition of finite $L S S$. In the subsequent discussion, the energy consumed in the rock under the ideal loading condition to yield the postpeak load-deformation curve is denoted as $\Delta E_{\mathrm{r}}^{\mathrm{B}}$ (red filled area), as opposed to $\Delta E_{\mathrm{r}}$ which is under the loading condition of finite $L S S$.

\section{Figure 4 Energy transfer in rock specimen-test machine system during the rock failure process when $L S S<\lambda$ (loading condition of unstable rock failure).}

A test machine with $L S S=\infty$ cannot store and release any energy (red dash line). Hence $\Delta E_{\mathrm{r}}^{\mathrm{B}}$ has to be provided exclusively by additional energy $\Delta E_{\text {in }}$ input from an external energy source. However, a test machine with $L S S<\lambda$ can store and then release a large amount of energy $\Delta E_{\mathrm{t}}$ (light blue filled area left to the ordinate) in the post-peak deformation stage so that 
$\Delta E_{\mathrm{t}}$ is more than the amount of energy that the rock needs to deform $\left(\Delta E_{\mathrm{t}}>\Delta E_{\mathrm{r}}^{\mathrm{B}}\right)$. Meanwhile, if the external energy source is still involved in the rock specimen-test machine system (e.g., loading ram is still driven by the external energy source), $\Delta E_{\text {in }}$ (light green filled area) is provided to the rock in addition to $\Delta E_{\mathrm{t}}$. As a result, the extra energy of $\Delta E_{\mathrm{t}}$ (light blue filled area right to red filled area) and $\Delta E_{\text {in }}$ makes up an energy surplus that leads to unstable rock failure. Experimental and numerical studies have demonstrated that rock failures are violent when $L S S<$ $\lambda$ (Cook 1965; Feng et al. 2016; He et al. 2015; Hudson et al. 1972; Manouchehrian and Cai 2015; Zhao and Cai 2014). Unfortunately, $\Delta E_{\text {in }}$ in these studies was not isolated to examine the influence of $\Delta E_{\mathrm{t}}$ on rock instability.

\section{Energy transfer under critical loading condition (LSS = $\lambda$ )}

$L S S=\lambda$ is the critical loading condition to ensure stable rock failure, and it is illustrated in Figure 5. As shown in Figure 5, no additional input energy $\Delta E_{\text {in }}$ is required for a test machine with $L S S=\lambda$ to obtain the post-peak load-deformation curve of the base case because the strain energy released from the test machine is just the right amount needed to drive rock failure $\left(\Delta E_{\mathrm{t}}=\right.$ $\left.\Delta E_{\mathrm{r}}=\Delta E_{\mathrm{r}}^{\mathrm{B}}\right)$. Hence, the post-peak deformation behavior of the rock with the energy provided exclusively from the test machine with $L S S=\lambda$ should be stable and close to that of the base case.

\section{Figure 5 Energy transfer in rock specimen-test machine system during the rock failure process when $L S S=\lambda$ (critical loading condition of stable rock failure).}

The rock failure process is nevertheless unstable or marginally stable if $\Delta E_{\text {in }}$ is supplied to the rock specimen-test machine system because there will be an energy surplus for the rock 
failure process. Note that the post-peak load-deformation curve simplified by a straight line is rarely the case for rock in reality, whose curve is prevalently nonlinear (Wawersik and Fairhurst 1970). For nonlinear post-peak deformation behavior, $\lambda$ refers to the slope at the point in the descending load-deformation curve is the steepest (Salamon 1970). Therefore, to obtain the complete post-peak load-deformation curve under the loading condition of $L S S=\lambda$, either some $\Delta E_{\text {in }}$ is required, or $L S S$ has to be slightly smaller than $\lambda$.

It is practically impossible to have a test machine with $L S S$ the same as the post-peak stiffness of a rock. As a result, there are no laboratory observations on the post-peak deformation behavior of rock under the critical loading condition. On the other hand, as will be highlighted in this study, numerical experiment is a promising approach to study how LSS affects the rock failure process. 2D numerical modeling results using the Discrete Element Method found that the post-peak stress-strain curve of rock under the critical loading condition was close to that under a rigid loading condition $(L S S=\infty)$ (Kias and Ozbay 2013). This observation was confirmed by Manouchehrian and Cai (2015) using a 3D Finite Element Method (FEM) numerical model. They further categorized the rock failure type under $L S S=\lambda$ as a transition type between stable and unstable rock failures. However, $\Delta E_{\text {in }}$ was not excluded in previous numerical models (Hemami and Fakhimi 2014; Kias and Ozbay 2013; Manouchehrian and Cai 2015) and the rock failure processes observed were the product of $\Delta E_{\mathrm{t}}$ plus $\Delta E_{\text {in }}$.

\section{Energy transfer under stable loading condition (LSS $>\lambda$ )}

Figure 6 illustrates the energy transfer in the rock specimen-test machine system during the rock failure process when $L S S>\lambda$. According to the stable rock failure criterion, the rock behavior under the loading condition of LSS $>\lambda$ is stable because the strain energy $\Delta E_{\mathrm{t}}$ released from a 
test machine with $L S S>\lambda$ to the rock is not sufficient to induce unstable rock failure $\left(\Delta E_{\mathrm{t}}<\right.$ $\left.\Delta E_{\mathrm{r}}^{\mathrm{B}}\right)$. Furthermore, a test machine with $L S S>\lambda$ cannot capture the post-peak load-deformation curve of rock without the additional energy $\Delta E_{\text {in }}$ input from the external energy source.

\section{Figure 6 Energy transfer in rock specimen-test machine system during the rock failure process when $L S S>\lambda$ (general loading condition of stable rock failure).}

If $\Delta E_{\text {in }}$ is provided during the rock failure process, the rock failure type under the loading condition of $L S S>\lambda$ depends upon the amount of $\Delta E_{\text {in. }}$ When the energy deficit illustrated in Figure 6 is offset by some $\Delta E_{\text {in }}$, the rock failure process will be driven in a stable manner and the post-peak load-deformation curve can be captured. However, if $\Delta E_{\text {in }}$ provided from the external energy source is too much that creates an energy surplus (light green filled area), the rock failure process can be violent. In other words, the rock failure type under the loading condition of $L S S>$ $\lambda$ can be varied if $\Delta E_{\text {in }}$ is drastically different. In other words, $L S S>\lambda$ as documented in the literature (Cook 1965; Salamon 1970) is not an absolute condition of stable rock failure. This is a new understanding on rock failure and the details are presented in Sections of numerical models and modeling parameters and of modeling results and discussions.

Figure 7 presents a simple case where different failure types of the same rock are expected under the same $L S S$ ( $L S S$ is higher than $\lambda$ but not extremely stiff) but different $\Delta E_{\text {in }}$. $\Delta E_{\text {in }}$ is provided by the displacement-controlled loading method through the same test machine. The test machine is simplified as a loading platen on top of the rock. The loading velocity $V_{a}$ applied to the rock is small, the rock is thus subjected to a quasi-static loading condition (i.e., the loading condition employed to obtain the post-peak deformation behavior in 
rock laboratory testing). The rock failure processes under the quasi-static loading when $L S S>\lambda$ are stable (Hudson and Harrison 2000; Stavrogin and Tarasov 2001).

\section{Figure 7 Schematic of different rock failure processes under same $L S S>\lambda$ while input energy is drastically different.}

If the rock is under an applied loading velocity of $V_{b}>V_{a}$, e.g., Split Hopkinson Pressure Bar testing to determine the dynamic stress-strain response of rock (Cai et al. 2007a; Frew et al. 2001), the rock is subjected to a dynamic loading condition. $\Delta E_{\text {in }}{ }^{\mathrm{b}}$ under the dynamic loading condition is much greater than $\Delta E_{\text {in }}{ }^{\text {a }}$ under the quasi-static loading condition. As a result, the rock failure process with $\Delta E_{\text {in }}{ }^{\mathrm{b}}$ can be violent even if $\Delta E_{\mathrm{t}}$ under these two loading conditions are the same. Recently, Xu and Cai (2016) confirmed that the loading method can affect the postpeak deformation behavior of rock even the rock is under the loading condition of the same $\operatorname{LSS}$ (> $\lambda$ ). In the field, the unstable rock failure illustrated in Figure 7 is compared to the rock failure under the stable loading condition with $L M S>\Lambda$ (refer to Eq. (4)). In such a case, rock instability can occur if there is a sudden seismic event on site and the seismic waves load the rock at a high loading rate (Holub et al. 2011). Note that the following numerical investigation focuses on the influence of $\Delta E_{\mathrm{t}}$ on the post-peak rock failure process.

\section{Numerical models and modeling parameters}

A numerical experiment approach (Cai 2008) is adopted to investigate the energy transfer in rock failure process. Previous numerical experiments focused on unstable loading condition and the additional energy input from the external energy source $\Delta E_{\text {in }}$ to facilitate the rock failure process was not excluded, i.e., the loading velocity applied by the external energy source through the test machines was maintained to deform the rock in the post-peak deformation stage. In addition, the 
loading condition at either laboratory or field scale is mostly quasi-static. Compared with unstable rock failure subjected to excess $\Delta E_{\text {in }}$ under a fast loading rate condition, $\Delta E_{\text {in }}$ under the quasi-static loading condition is supplied slowly to ensure that the rock failure process is stable. On the other hand, as discussed in Section of theoretical analysis of the energy transfer in rock failure process, $\Delta E_{\mathrm{t}}$ can have a great impact on the rock failure process. Consequently, the following study will focus on the strain energy $\Delta E_{\mathrm{t}}$ released from test machines and how it affects rock failure. To achieve this goal, the post-peak deformation behavior of the base case under the ideal loading condition (refer to Section of energy transfer under unstable loading condition) is defined first. In addition, a numerical model that can realistically characterize the structural response of stiff test machines in the rock failure process is constructed.

\section{Statement for assumed post-peak behavior of rock}

The numerical experiment is performed using ABAQUS $^{2 D}$ (ABAQUS 2010). ABAQUS ${ }^{2 D}$ is a powerful FEM tool in solving highly nonlinear structure system problems under transient loads by employing the explicit algorithm. Obviously, it is difficult to calibrate the post-peak deformation behavior of rock in the numerical experiment by referring to the laboratory test results because the mechanical behavior of rock is essentially heterogeneous (Feng and Hudson 2010; Martin and Chandler 1994; Tang et al. 2000). In the post-peak deformation stage, localized failure normally takes place (Bobet and Einstein 1998; Hudson and Harrison 2001; Rudnicki and Rice 1975; Shao et al. 2005). In addition, direct measurement of the stress state and the development of plastic strain in specimens in laboratory tests is difficult. Hence, the post-peak deformation behavior is prescribed in the numerical experiment.

Uniaxial compression test is widely used in rock property testing and the numerical experiment is restricted to this type of compression test. The post-peak deformation behaviors of 
rock in uniaxial compression are usually classified into Class I and Class II failure types (Wawersik and Fairhurst 1970). Class I failure type is chosen for the post-peak deformation behavior of rock in this study because it shows a strain-softening behavior, which is commonly observed in uniaxial compression test results (Lockner 1995; Martin and Chandler 1994) and can be easily obtained using the axial-strain-controlled loading in the numerical experiment. More importantly, using the axial-strain-controlled loading might be more appropriate to reflect the actual loading condition in situ. For instance, the loading condition in a pillar is axialdeformation controlled loading, and the in situ complete load-deformation curves of pillars obtained by field testing so far show mostly Class I failure type (Cook et al. 1971; Van Heerden 1975).

\section{Base case under the ideal loading condition}

Based on the International Society for Rock Mechanics suggested methods for determining uniaxial compression strength (Fairhurst and Hudson 1999), a rectangular specimen with a height of $100 \mathrm{~mm}$ and a width of $50 \mathrm{~mm}$ is used for the simulation. Shear constraint along the platen-specimen contact surfaces is excluded using frictionless contact. The pre-peak deformation behavior of the rock is simplified as linear elastic. M-C failure criterion with a tension cut-off is employed to determine the peak strength of the rock. The mechanical parameters of the rock are presented in Table 1.

\section{Table 1 Mechanical parameters of the rock}

Strain-softening behavior is assumed for the post-peak deformation behaviors of the rock. On one hand, this study focuses on the post-peak stress-strain curves of rock, and the simulation of fracture process at the microscopic scale is beyond the scope this research. On the other hand, 
the fracture process in the post-peak deformation stage marks the breakage of rock structure, leading to cohesion loss (Martin 1997). Accordingly, the strain-softening behavior of the rock can be defined by degrading the cohesion strength of the rock as a function of plastic strain (Table 2).

\section{Table 2 Strain-softening parameters of the rock in simulation}

The stress-strain curve for the base case is obtained by applying a constant loading velocity of $0.016 \mathrm{~m} / \mathrm{s}$ symmetrically onto the specimen's top and bottom ends as shown in Figure 8 (note that the loading velocity applied using an explicit algorithm for solving quasi-static problems is not comparable to that used real rock testing). This loading method implies that the $L S S$ in the loading direction of the specimen is infinite $(\infty)$ and it is referred as the ideal loading condition. The size of the elements is $2.5 \mathrm{~mm}$ in its longest dimension; the maximum deviation factor for the curvature control of element size is 0.1 . The shape of the elements is quad; the elements are generated by using the structured technique. The element type is 4-node bilinear plane strain quadrilateral; the integration algorithm for the chosen element type is reduced integration using hourglass control.

\section{Figure 8 Rock specimen under uniaxial compression applied by the ideal loading condition: (a) schematic of the loading condition, and (b) FEM model.}

Figure 9 presents the complete stress-strain curve of the rock under the ideal loading condition in uniaxial compression. It will be used for comparing with other results obtained from a test machine with various $L S S$ values. The steepest descending slope of the curve is indicated by a red dash line cutting through a red point circle, near which it tells that the post-peak 
stiffness of the rock in the stress-strain space $\left(E_{\mathrm{p}}\right)$ is $47 \mathrm{GPa}$, or $\lambda=24 \mathrm{GN} / \mathrm{m}$ if the loaddeformation relation is used (refer to Eq. (1)).

\section{Figure 9 Stress-strain curve of a rock specimen under the ideal loading condition in uniaxial compression.}

\section{Numerical model of traditional stiff test machines}

In this section, the numerical model of stiff test machines is introduced. Figure 10 presents the numerical model, which is an idealized conceptualization of the traditional stiff test machines (Figure 1). Two loading platens of the same geometry are in contact with the specimen and a loading frame encapsulating the specimen-platen complex is incorporated. Note that the actual geometrical relation between the test machine and the rock specimen is considered in a qualitative manner because precise modeling of all the components in a test machine is beyond the intended scope of this study.

\section{Figure 10 Rock specimen under uniaxial compression applied by the frame-platen loading} condition: (a) schematic of the loading condition, and (b) FEM model.

Inspired by the thermal loading mechanism developed by Cook and Hojem (1966) and Wawersik (1968) independently, the loading platen underneath the specimen is assigned an orthotropic thermal property, i.e., thermal expansion of the platen occurs only in the vertical direction (parallel to the specimen height) and the thermal expansion in the horizontal direction is zero. This is an attempt to simulate the loading ram in a traditional stiff test machine and in this fashion the loading frame that encapsulates the specimen-platen-ram complex similar to that shown in Figure 1 can be imbedded in the numerical model. 
Because the loading platen at the bottom consists of an idealized material, it is called the thermal loading platen and the test machine is called the frame-platen loading test machine. When a constant heat flux is provided to the thermal loading platen, it will expand linearly in the vertical direction to contract the rock specimen in a way similar to that a fluid loading ram does. In reality, the fluid in a fluid loading ram can reduce $L S S$. If such a frame-platen loading test machine is not used, high $L S S$ values cannot be achieved both in laboratory test and in numerical modeling. Consequently, this loading condition is termed as the frame-platen loading condition.

The heat flux applied to the thermal loading platen is calibrated so that the specimen under the frame-platen loading condition is contracted at a displacement rate the same as that in the ideal loading condition. Table 3 presents the calibrated thermal parameters for the thermal loading platen.

\section{Table 3 Calibrated thermal parameters for the thermal loading platen used in simulation}

Figure 11 compares the calibrated displacement-time relation of the specimen under the frame-platen loading condition with that under the ideal loading condition. The displacement under the frame-platen loading condition is recorded at the top end of the thermal loading platen, and the whole body of which is continuously exposed to a constant heat flux.

\section{Figure 11 Displacement-time relations of rock specimens under two loading conditions.}

The Young's moduli of the loading frame and the platens are the same. They are varied simultaneously to change LSS. According to the definition of stiffness (Section of stable rock failure criterion and energy transfer in rock failure process), Figure 12 illustrates how the LSS of the frame-platen loading test machine is calibrated in the numerical modeling. If a pair of 
concentrated reaction load $(F)$ is applied to the top and bottom loading platens through two rigid platens, the relative displacement $\left(\delta_{1}+\delta_{2}\right)$ of these two rigid platens will cause an elastic response of the test machine.

\section{Figure 12 Calibration of frame-platen loading test machine's LSS in numerical modeling.}

Figure 13 illustrates the load-displacement relation of the frame-platen loading test machine calibrated for the case of unstable failure. Based on the slope of the fitting line for this load-displacement relation, $L S S$ is interpreted as $15 \mathrm{GN} / \mathrm{m}$ and it is less than $\lambda=24 \mathrm{GN} / \mathrm{m}$ (Figure 9). In this way, the Young's modulus of the frame-platen loading test machine can be adjusted to yield different loading conditions of $L S S$. In the numerical experiment, $L S S=61$ $\mathrm{GN} / \mathrm{m}$ is calibrated for the stable failure condition. For the critical loading condition, in addition to $L S S=24 \mathrm{GN} / \mathrm{m}$, a case with $L S S=19 \mathrm{GN} / \mathrm{m}$, which is slightly lower than $\lambda$, is calibrated to ensure that the post-peak deformation behavior of the rock can be observed when the external energy supply is cut off at the peak load (refer to the explanation in Section of energy transfer under critical loading condition). Ideally, this should occur under the condition of $L S S=\lambda$. A marginally critical loading condition of LSS (slightly lower than $\lambda$ ) is largely due to the fact the post-peak stress-strain curve of the rock is nonlinear. As a result, at least three rock failure types are expected: stable for $61 \mathrm{GN} / \mathrm{m}$, critical for $24 \mathrm{GN} / \mathrm{m}$, marginally critical for $19 \mathrm{GN} / \mathrm{m}$, and unstable for $15 \mathrm{GN} / \mathrm{m}$.

Figure 13 Calibrated load-displacement relations of the frame-platen loading test machine.

\section{Modeling results and discussions}


In the numerical experiment, the accumulative energy $E_{\text {in }}{ }^{*}$ input from the external energy source at a point in the post-peak deformation stage is nixed by cutting off the constant heat flux supply of the thermal loading platen underneath the rock specimen. As a result, the external energy supplied to the rock specimen-test machine system is stopped and $E_{\text {in }}{ }^{*}$ becomes constant starting from this moment. In laboratory testing, this is in accordance with cutting off the oil supply of the loading ram so that loading is stopped but the position of the ram is maintained. In underground engineering settings, it is equivalent to the cease of tunnel face advance.

As soon as the external energy supply is stopped, the energy released from the test machine $\Delta E_{\mathrm{t}}$, which is due to the reduction of strain energy stored in the test machine from the peak load to some strain levels at the post-peak deformation stage $\left(E_{\mathrm{t}}-E_{\mathrm{t}}^{*}\right)$, becomes the only energy item that can possibly further deform the rock in the post-peak deformation stage (refer to Eq. (8)). The time to stop $E_{\mathrm{in}}{ }^{*}$ is varied under different loading conditions of LSS to ensure that the rock failure process can be at least observed in part and the influence of $\Delta E_{\mathrm{t}}$ on the rock failure process can be studied.

\section{Stable loading condition ( $L S S>\lambda$ )}

Figure 14 presents the stress-strain curves of the rock under the stable loading condition of LSS $=61 \mathrm{GN} / \mathrm{m}$ and the ideal loading condition, along with the accumulative energy $E_{\mathrm{in}}{ }^{*}$ and $E_{\mathrm{t}}{ }^{*}$ during the entire deformation process. In this case, the external energy is supplied in the whole deformation process until at Point A.

Figure 14 Stress-strain curve of the rock under $L S S=61 \mathrm{GN} / \mathrm{m}$ and the ideal loading condition, along with the accumulative energy $E_{\text {in }}{ }^{*}$ and $E_{\mathrm{t}}{ }^{*}$. 
$E_{\text {in }}{ }^{*}$ is stopped at an axial strain of $\varepsilon=0.33 \%$ (Point A) when an obvious strain-softening behavior can be identified. The deviation of the stress-strain curve under finite LSS from that under the ideal loading condition $(L S S=\infty)$ was investigated by Xu and Cai (2016). $E_{\mathrm{t}}^{*}$ reaches its peak value at the same axial strain as the peak strength of the rock (according to the definition in Section of stable rock failure criterion and energy transfer in rock failure process, the energy item at the peak load is $E_{\mathrm{t}}$ ). Then, $E_{\mathrm{t}}{ }^{*}$ decreases as the rock enters into its post-peak deformation stage. The decrease of $E_{\mathrm{t}}{ }^{*}$ marks the release of stored strain energy from the test machine $\Delta E_{\mathrm{t}}(=$ $\left.E_{\mathrm{t}}-E_{\mathrm{t}}^{*}\right)$. Because $L S S$ is relatively stiff, $E_{\mathrm{t}}$ is small and so is $\Delta E_{\mathrm{t}}$.

As soon as the external energy input $E_{\mathrm{in}}{ }^{*}$ is stopped, $\Delta E_{\mathrm{t}}$ since then becomes the only energy item available for the rock deformation. It is seen that the rock deformation terminates at $\varepsilon=0.33 \%$, at the same axial strain where the external energy input $E_{\mathrm{in}}{ }^{*}$ is stopped. Rock failure under this loading condition is stable. In other words, $\Delta E_{\mathrm{t}}$ alone cannot drive the rock failure process further; the rock failure process cannot proceed from Point A without addition energy $\Delta E_{\text {in }}$ input from the external energy source. This is in agreement with the theory of stable rock failure (Section of stable rock failure criterion and energy transfer in rock failure process).

\section{Critical loading condition ( $L S S=\lambda)$}

Figure 15 presents the stress-strain curves of the rock under the critical loading condition of LSS $=\lambda$ and the ideal loading condition, along with the accumulative energy $E_{\mathrm{in}}{ }^{*}$ and $E_{\mathrm{t}}{ }^{*}$ during the whole deformation process. As justified in Section of energy transfer under critical loading condition $(L S S=\lambda)$, in order to observe the post-peak deformation behavior of rock under the critical loading condition, either a small $\Delta E_{\text {in }}$ is required or $L S S$ has to be slightly lower than $\lambda$. Hence, for the first approach, $E_{\mathrm{in}}{ }^{*}$ is continued in the post-peak deformation stage until an axial 
strain of $\varepsilon=0.32 \%$ is reached (Point A), at which the descending slope of the strain-softening curve becomes steep and approaches the post-peak stiffness of the rock.

\section{Figure 15 Stress-strain curves of the rock under $L S S=24 \mathrm{GN} / \mathrm{m}$ and the ideal loading condition, along with the accumulative energy $E_{\mathrm{in}}{ }^{*}$ and $E_{\mathrm{t}}{ }^{*}$.}

The rock continues to deform post Point $\mathrm{A}$ after ${E_{\mathrm{in}}}^{*}$ is stopped. It is seen that the stress drop of the strain-softening curve follows a path the same as the unloading path of the test machine in the stress-strain space for $L S S=24 \mathrm{GN} / \mathrm{m}$ (refer to the unloading behavior of test machine illustrated in Figure 5). Rock deformation terminates at an axial strain of $\varepsilon=0.47 \%$ (Point B) at which there is a large energy deficit between the strain-softening curve under the critical loading condition and that under the ideal loading condition.

Comparing with the result shown in Figure 14, more strain energy is stored in the test machine in this case. $E_{\mathrm{t}}{ }^{*}$ decreases in the post-peak deformation stage until at Point $\mathrm{B}$, where there is a large energy deficit. $E_{\mathrm{t}}{ }^{*}$ is minimal at Point B; in other words, there is a small amount of strain energy left in the test machine as the deformation stopped at Point B. As a result, even if there is strain energy $\Delta E_{\mathrm{t}}$ released from the test machine at the early stage of the rock failure process, the rock deformation process cannot proceed further beyond Point B unless addition energy $\Delta E_{\text {in }}$ is supplied from the external energy source to the rock.

Figure 16 presents the results of the second approach for observing the stress-strain curve under the marginally critical loading condition by using a slightly smaller $L S S=19 \mathrm{GN} / \mathrm{m}$. In this case, $E_{\text {in }}{ }^{*}$ is stopped at Point $\mathrm{A}$ as soon as the peak strength of the rock has been reached.

\section{Figure 16 Stress-strain curve of the rock under $L S S=19 \mathrm{GN} / \mathrm{m}$ and the ideal loading} condition, along with the accumulative energy $E_{\mathrm{in}}{ }^{*}$ and $E_{\mathrm{t}}$. 
Three characteristics of the strain-softening curve under $L S S=19 \mathrm{GN} / \mathrm{m}$ are identified. First, $L S S=19 \mathrm{GN} / \mathrm{m}$ is slightly smaller than $\lambda$, and $\lambda$ is defined by the steepest descending slope in the load-deformation space and it occurs approximately at an axial strain $\varepsilon=0.4 \%$ in the stress-strain space (refer to the red circle in Figure 9). The post-peak stiffness of the rock at its early post-peak deformation stage ( $\varepsilon=0.32$ to $0.35 \%$ ) is close to $L S S=19 \mathrm{GN} / \mathrm{m}$. Hence, the strain-softening curve under $L S S=19 \mathrm{GN} / \mathrm{m}$ is close to that under the ideal loading condition at the early stage of rock failure.

Then, as rock deformation continues, the post-peak stiffness of the rock becomes stiffer than $L S S$. In such a case, the strain-softening curve under $L S S=19 \mathrm{GN} / \mathrm{m}$ is more ductile than that of the base case. The difference between these two curves results in an energy surplus (e.g., the big energy surplus at Point C), thus the rock failure process should be somewhat violent when there is an energy surplus. In the end, the strain-softening curve under $L S S=19 \mathrm{GN} / \mathrm{m}$ comes to a halt at an axial strain of $\varepsilon=0.56 \%$, where there is an energy deficit that terminates the deformation of the rock at Point B.

\section{Unstable loading condition (LSS $<\lambda$ )}

Figure 17 presents the stress-strain curves of the rock under the unstable loading condition with $L S S=15 \mathrm{GN} / \mathrm{m}$ and the ideal loading condition, along with the accumulative energy $E_{\mathrm{in}}{ }^{*}$ and $E_{\mathrm{t}}{ }^{*}$

during the whole deformation process. In this case, $E_{\mathrm{in}}{ }^{*}$ is stopped as soon as the peak strength of the rock has been reached (Point A).

A machine with softer $L S S$ stores more strain energy. Compared with $E_{\mathrm{t}}$ in previous three cases (Figure 14 to Figure 16 ), $E_{\mathrm{t}}$ is the highest under $L S S=15 \mathrm{GN} / \mathrm{m}$ because it is the softest loading condition. Thus, the strain energy $\Delta E_{\mathrm{t}}$ released from the test machine with $L S S=15$ 
$\mathrm{GN} / \mathrm{m}$ should be sufficient for driving the rock failure process. It is seen that driven by $\Delta E_{\mathrm{t}}$ released from the test machine, the rock continues to deform after Point $\mathrm{A}$ in the post-peak deformation stage and that in turn promotes stress decrease.

\section{Figure 17 Stress-strain curves of the rock under $L S S=15 \mathrm{GN} / \mathrm{m}$ and the ideal loading condition, along with the accumulative energy $E_{\text {in }}{ }^{*}$ and $E_{\mathrm{t}}{ }^{*}$.}

The stress drop of the strain-softening curve follows a path the same as the unloading path of the test machine in the stress-strain space for $L S S=15 \mathrm{GN} / \mathrm{m}$. The strain-softening curve under $L S S=15 \mathrm{GN} / \mathrm{m}$ is more ductile than that under the ideal loading condition. The energy surplus indicates that there is extra energy released from the test machine to drive the rock failure process. In laboratory testing, this amount of extra energy, which cannot be absorbed completely during the rock failure process, has to be dissipated in a violent form often associated with rock ejection. Therefore, the rock failure under this loading condition is unstable.

\section{Short summary}

In the above discussions, the rock failure processes under different loading conditions of different LSS were analyzed in terms of consumed energy difference based on the strainsoftening curves. In this section, the rock failure process is interpreted in a more quantitative way using an indicator of unstable rock failure. According to the indicator proposed by Manouchehrian and Cai (2015) to distinguish between stable and unstable rock failures in laboratory testing, loading system reaction intensity $(L S R I)$ is defined as the ratio of the maximum reaction velocity $\left(V_{\max }\right)$ of the loading platen (or test machine) at the rock specimenloading platen contact to the applied loading velocity $\left(V_{0}\right)$ at the other end of the platen (Figure 18). $V_{0}$ at the boundary is constant; however, $V_{\max }$ at the rock specimen-loading platen contact 
varies (unless the loading platen is a rigid body), depending on the relation between LSS and the post-peak stiffness of the rock specimen.

\section{Figure 18 Calculation of LSRI (after Manouchehrian and Cai 2015).}

Table 4 shows the relation between LSRI and LSS. Manouchehrian and Cai (2015) pointed out that $L S R I$ is normally smaller than 2 for stable rock failure; LSRI of 2 to 4 can be loosely regarded as transition between the stable and the unstable rock failures. It is seen that even though $\Delta E_{\text {in }}$ is isolated from the energy transfer in the rock failure process, the $L S R I$ values can be used to identify rock failure type. Hence, it is demonstrated that depending on the $L S S$ of a test machine, the strain energy released from the test machine alone without additional energy supply can drastically affect the rock failure process.

\section{Table 4 Relation between $L S R I$ and $L S S$ together with rock failure types interpreted}

The rock failure process under the marginally critical loading condition $(L S S=19 \mathrm{GN} / \mathrm{m})$ is discussed because there are three distinct characteristics identified for the strain-softening curve (Figure 16). As demonstrated previously, LRSI is useful in determining if a rock failure process is violent or not because the reaction velocity at the rock specimen-loading platen contact is associated with the rock failure process. Figure 19 presents the variation of the reaction velocity (positive velocity is in the same direction as the applied velocity direction of $V_{0}$ ) with time for the rock under $L S S=19 \mathrm{GN} / \mathrm{m}$ in the post-peak deformation stage. The three points marked in Figure 19 are in accordance with the three points marked in the stress-strain curve shown in Figure 16. 


\section{Figure 19 Relation between reaction velocity and time for the rock under $L S S=19 \mathrm{GN} / \mathrm{m}$ in the post-peak deformation stage.}

At the early post-peak deformation stage when the external energy is stopped, the reaction velocity first decreases from the applied loading velocity $\left(V_{0}\right)$ to zero at about $0.016 \mathrm{~s}$. The post-peak stiffness of the rock at this stage is close to $L S S$ and the rock continues to deform. Next, as the post-peak stiffness of the rock becomes greater than $L S S$, the reaction velocity increases quickly and reaches a first peak and then drops slightly before reaching the maximum at Point $\mathrm{C}$, where the energy surplus is the largest (Figure 16). After Point $\mathrm{C}$, the reaction velocity decreases, followed by a decayed oscillation of the velocity. At the last post-peak deformation stage, the strain energy released from the test machine $\Delta E_{\mathrm{t}}$ decreases and the oscillatory reaction velocity further decreases and reaches 0 at Point $\mathrm{B}$, where the rock deformation stops.

The oscillatory reaction velocity in the post-peak deformation stage captured in the numerical experiment (Figure 19) might somehow reflect the reaction velocity in reality. Slow motion videos recorded in unstable rock failure in laboratory tests show first a large downward movement of the top loading platen, followed by smaller up-and-down movements. An explanation accounting for the oscillation of reaction velocity is given in Figure 20. If the loading ram is represented by a spring and $V_{0}$ is applied through a boundary surface attached to one end of the spring, stiffness at the boundary surface is $\infty$ because of the displacementcontrolled loading. There is another contact surface attached to the other end of the spring, which is in contact with the rock specimen. When the strain energy is released from the test machine (spring), and if the test machine is relatively soft, the contact surface will oscillate. The 
oscillatory reaction velocity at the contact surface will decay when the released strain energy becomes small.

\section{Figure 20 Explanation for the oscillatory reaction velocity in the post-peak deformation} stage.

\section{Conclusions}

The strain energy released from test machines or surrounding rock masses is long speculated to be able to cause rock instability in laboratory testing and underground excavations. It is difficult to use the laboratory or the field experimental approach to test the hypothesis. Numerical experiment approach provides a solution to the problem.

In the numerical experiment, the post-peak stress-strain curves of a rock under different loading conditions of $L S S$ were examined using a novel test machine model where the energy input from the external energy source to drive rock failure can be easily isolated. The modeling results demonstrate that even if the external energy supply to the test machine is cut off at the post-peak deformation stage, the rock can fail as long as the strain energy released from the test machine is sufficient to drive the rock failure process. In particular, if the strain energy released from a soft test machines has surplus during the post-peak deformation stage, the rock failure process can be violent. To avoid such failures, simply stopping or retracting the advancement of the loading ram is not be enough; the $L S S$ of a test machine has to be stiffer than the post-peak stiffness of the rock, or the surplus energy has to be removed from the test machine. Removing surplus energy from the test machine is the soul of a servo-controlled test machine. In most test machines that use oil pump to apply load, the LSS of the machines are low and it is necessary to unload or remove energy from the test machine quickly in order to avoid violent rock failure. 
The conclusions drawn from the modeling results on laboratory testing can also be applied to explaining the mechanism of some delayed rockbursts (refer to Section of indirect observations on the strain energy released from test machines or surrounding rock masses and its impact on rock stability). Note that the explanation for the delayed rockburst given in study is related to the creep behavior of rock, which was not incorporated in the material model of the numerical experiment. This is a planned research in the future.

\section{Acknowledgements}

This work was financially supported by NSERC (Natural Science and Engineering Research Council of Canada) and the Open Research Fund of the Key Laboratory of Ministry of Education for Safe Mining of Deep Metal Mines, Northeastern University, China.

\section{References}

ABAQUS. 2010. Abaqus 6.10: Analysis user's manual. Dassault Systèmes Simulia Corp, Providence.

Alonso, E., Alejano, L., Varas, F., Fdez-Manin, G., and Carranza-Torres, C. 2003. Ground response curves for rock masses exhibiting strain - softening behaviour. International Journal for Numerical and Analytical Methods in Geomechanics 27(13): 1153-1185.

Baumgart, F. 2000. Stiffness - an unknown world of mechanical science? Injury-International Journal for the Care of the Injured 31(2): 14-23.

Bieniawski, Z. 1966. Mechanism of rock fracture in compression. Mech. Eng. Inst., S. Afr. Counc. Sci. Ind. Res. p. 77.

Bieniawski, Z.T. 1967. Mechanism of brittle fracture of rock: part I-theory of the fracture process. International Journal of Rock Mechanics and Mining Sciences \& Geomechanics Abstracts 4(4): 395-406. 
Bieniawski, Z.T., Denkhaus, H.G., and Vogler, U.W. 1969. Failure of fractured rock. International Journal of Rock Mechanics and Mining Sciences \& Geomechanics Abstracts 6(3): 323-341.

Blake, W., and Hedley, D.G. 2003. Rockbursts: case studies from North American hard-rock mines. Society for Mining, Metallurgy, and Exploration, Littleton, Colorado.

Bobet, A. 2001. Influence of the loading apparatus on the stresses within biaxial specimens. ASTM Geotechnical Testing Journal 24(3): 256-272.

Bobet, A., and Einstein, H. 1998. Fracture coalescence in rock-type materials under uniaxial and biaxial compression. International Journal of Rock Mechanics and Mining Sciences 35(7): 863-888.

Brady, B.H., and Brown, E.T. 2013. Rock mechanics: for underground mining. Springer Science \& Business Media.

Cai, M. 2008. Influence of intermediate principal stress on rock fracturing and strength near excavation boundaries - insight from numerical modeling. International Journal of Rock Mechanics and Mining Sciences 45(5): 763-772.

Cai, M., Kaiser, P., Suorineni, F., and Su, K. 2007a. A study on the dynamic behavior of the Meuse/Haute-Marne argillite. Physics and Chemistry of the Earth 32(8): 907-916.

Cai, M., Kaiser, P., Tasaka, Y., and Minami, M. 2007b. Determination of residual strength parameters of jointed rock masses using the GSI system. International Journal of Rock Mechanics and Mining Sciences 44(2): 247-265.

Chen, B.-R., Feng, X.-T., Ming, H.-J., Zhou, H., Zeng, X.-W., Feng, G.-L., and Xiao, Y.-X. 2012. Evolution law and mechanism of rockburst in deep tunnel: time delayed rockburst. Chinese Journal of Rock Mechanics and Engineering 31(3): 561-569.

Chen, W.F., and Han, D.J. 2007. Plasticity for structural engineers. J. Ross Publishing.

Cook, N. 1965. The failure of rock. International Journal of Rock Mechanics and Mining Sciences 2: 389-403.

Cook, N.G.W., Hodgson, K., and Hojem, J.P.M. 1971. A 100 MN jacking system for testing coal pillars underground. Journal of the Southern African Institute of Mining and Metallurgy 71: $215-224$.

Cook, N.G.W., and Hojem, J.P.M. 1966. A rigid 50-ton compression and tension testing machine. Journal of the Southern African Institute of Mining and Metallurgy 1: 89-92. 
Cook, N.G.W., and Hojem, J.P.M. 1971. A 200-ton stiff testing machine. Journal of the Southern African Institute of Mining and Metallurgy.

Fairhurst, C., and Hudson, J. 1999. Draft ISRM suggested method for the complete stress-strain curve for intact rock in uniaxial compression. International Journal of Rock Mechanics and Mining Sciences 36(3): 279-289.

Feng, X.-T., and Hudson, J.A. 2010. Specifying the information required for rock mechanics modelling and rock engineering design. International Journal of Rock Mechanics and Mining Sciences 47(2): 179-194.

Feng, X., Zhang, X., Kong, R., and Wang, G. 2016. A novel Mogi type true triaxial testing apparatus and its use to obtain complete stress-strain curves of hard rocks. Rock Mechanics and Rock Engineering 49(5): 1649-1662.

Frew, D., Forrestal, M., and Chen, W. 2001. A split Hopkinson pressure bar technique to determine compressive stress-strain data for rock materials. Experimental Mechanics 41(1): 40-46.

Goodman, R.E. 1989. Introduction to rock mechanics. Wiley New York.

Griggs, D.T. 1936. Deformation of rocks under high confining pressures: I. Experiments at room temperature. The Journal of Geology: 541-577.

Handin, J. 1953. An application of high pressure in geophysics: experimental rock deformation. Transactions American Society of Mechanical Engineers 75: 315-324.

He, M., Nie, W., Zhao, Z., and Guo, W. 2012. Experimental investigation of bedding plane orientation on the rockburst behavior of sandstone. Rock mechanics and rock engineering 45(3): 311-326.

He, M., Zhao, F., Cai, M., and Du, S. 2015. A novel experimental technique to simulate pillar burst in laboratory. Rock Mechanics and Rock Engineering 48(5): 1833-1848.

Heal, D. 2010. Observations and analysis of incidences of rockburst damage in underground mines. University of Western Australia, Australia.

Hemami, B., and Fakhimi, A. 2014. Numerical simulation of rock-loading machine interaction. In 48th US Rock Mechanics/Geomechanics Symposium. American Rock Mechanics Association. 
Holub, K., Rušajová, J., and Holečko, J. 2011. Particle velocity generated by rockburst during exploitation of the longwall and its impact on the workings. International Journal of Rock Mechanics and Mining Sciences 48(6): 942-949.

Hudson, J., Brown, E., and Fairhurst, C. 1971. Optimizing the control of rock failure in servocontrolled laboratory tests. Rock Mechanics 3(4): 217-224.

Hudson, J.A., Crouch, S.L., and Fairhurst, C. 1972. Soft, stiff and servo-controlled testing machines: a review with reference to rock failure. Engineering Geology 6(3): 155-189.

Hudson, J.A., and Harrison, J.P. 2000. Engineering rock mechanics - an introduction to the principles. Elsevier. pp. 457.

Hudson, J.A., and Harrison, J.P. 2001. Engineering rock mechanics - illustrative worked examples. Elsevier.

Jing, L. 2003. A review of techniques, advances and outstanding issues in numerical modelling for rock mechanics and rock engineering. International Journal of Rock Mechanics and Mining Sciences 40(3): 283-353.

Kias, E., and Ozbay, U. 2013. Modeling unstable failure of coal pillars in underground mining using the discrete element method. In 47th US Rock Mechanics/Geomechanics Symposium. American Rock Mechanics Association.

Kiendl, O.G., and Maldari, T. 1938. A comparison of physical properties of concrete made of three varieties of coarse aggregate. In Civil Engineering. University of Wisconsin.

Li, S., Feng, X.-T., Li, Z., Chen, B., Zhang, C., and Zhou, H. 2012. In situ monitoring of rockburst nucleation and evolution in the deeply buried tunnels of Jinping II hydropower station. Engineering Geology 137: 85-96.

Lockner, D.A. 1995. Rock failure. In Rock Physics \& Phase Relations: A Handbook of Physical Constants. American Geophysical Union Reference Shelf, Washington. pp. 127-147.

Malan, D. 1999. Time-dependent behaviour of deep level tabular excavations in hard rock. Rock Mechanics and Rock Engineering 32(2): 123-155.

Manouchehrian, A., and Cai, M. 2015. Simulation of unstable rock failure under unloading conditions. Canadian geotechnical journal 53(1): 22-34.

Martin, C. 1997. Seventeenth Canadian geotechnical colloquium: the effect of cohesion loss and stress path on brittle rock strength. Canadian Geotechnical Journal 34(5): 698-725. 
Martin, C., and Chandler, N. 1994. The progressive fracture of Lac du Bonnet granite. International Journal of Rock Mechanics and Mining Sciences \& Geomechanics Abstracts 31(6): 643-659.

Martin, C., and Maybee, W. 2000. The strength of hard-rock pillars. International Journal of Rock Mechanics and Mining Sciences 37(8): 1239-1246.

MTS, S.C. 2013. MTS Model 815 and 816 Rock Mechanics Test Systems. In User's manual.

Poplawski, R. 1997. Seismic parameters and rockburst hazard at Mt Charlotte mine. International Journal of Rock Mechanics and Mining Sciences 34(8): 1213-1228.

Rudnicki, J.W., and Rice, J. 1975. Conditions for the localization of deformation in pressuresensitive dilatant materials. Journal of the Mechanics and Physics of Solids 23(6): 371394.

Rummel, F., and Fairhurst, C. 1970. Determination of the post-failure behavior of brittle rock using a servo-controlled testing machine. Rock Mechanics 2(4): 189-204.

Salamon, M.D.G. 1970. Stability, instability and design of pillar workings. International Journal of Rock Mechanics and Mining Sciences \& Geomechanics Abstracts 7(6): 613-631.

Shao, J.-F., Chau, K.-T., and Feng, X.-T. 2006. Modeling of anisotropic damage and creep deformation in brittle rocks. International Journal of Rock Mechanics and Mining Sciences 43(4): 582-592.

Shao, J.-F., Zhou, H., and Chau, K. 2005. Coupling between anisotropic damage and permeability variation in brittle rocks. International Journal for Numerical and Analytical Methods in Geomechanics 29(12): 1231-1247.

Shao, J.-F., Zhu, Q.-Z., and Su, K. 2003. Modeling of creep in rock materials in terms of material degradation. Computers and Geotechnics 30(7): 549-555.

Snowdon, R., Ryley, M., Temporal, J., and Crabb, G. 1983. The effect of hydraulic stiffness on tunnel boring machine performance. International Journal of Rock Mechanics and Mining Sciences \& Geomechanics Abstracts 20(5): 203-214.

Stavrogin, A.N., and Tarasov, B.G. 2001. Experimental physics and rock mechanics. CRC Press.

Tang, C., Tham, L., Lee, P., Tsui, Y., and Liu, H. 2000. Numerical studies of the influence of microstructure on rock failure in uniaxial compression - part II: constraint, slenderness and size effect. International Journal of Rock Mechanics and Mining Sciences 37(4): 571-583. 
Tang, C., Yang, W., Fu, Y., and Xu, X. 1998. A new approach to numerical method of modelling geological processes and rock engineering problems - continuum to discontinuum and linearity to nonlinearity. Engineering Geology 49(3-4): 207-214.

Ulusay, R. 2015. The present and future of rock testing: highlighting the ISRM suggested methods. In The ISRM suggested methods for rock characterization, testing and monitoring: 2007-2014. Springer. pp. 1-22.

Van Heerden, W. 1975. In situ complete stress-strain characteristics of large coal specimens. Journal of the South African Institute of Mining and Metallurgy 75: 207-217.

Wawersik, W.R. 1968. Detailed analysis of rock failure in laboratory compression tests. University of Minnesota.

Wawersik, W.R., and Fairhurst, C.H. 1970. A study of brittle rock fracture in laboratory compression experiments. International Journal of Rock Mechanics and Mining Sciences \& Geomechanics Abstracts 7(5): 561-575.

Wu, Y., and Zhang, W. 1997. Prevention of rockbursts in coal mines in China. In Proceedings of the 4th International Symposium on Rockbursts and Seismicity in Mines, Rotterdam. pp. 361-366.

Xu, Y., and Cai, M. 2016. Influence of Loading System Stiffness on the Post-peak Behavior of Stable Rock Failures. Rock Mechanics and Rock Engineering: submitted.

Zhang, C., Feng, X.-T., Zhou, H., Qiu, S., and Wu, W. 2012. Case histories of four extremely intense rockbursts in deep tunnels. Rock mechanics and rock engineering 45(3): 275-288.

Zhao, X., and Cai, M. 2014. Influence of specimen height-to-width ratio on the strainburst characteristics of Tianhu granite under true-triaxial unloading conditions. Canadian Geotechnical Journal 52(7): 890-902.

Zipf, R.K., Jr. 1992. Analysis of stable and unstable pillar failure using a local mine stiffness method. In Proceedings of the Workshop on Coal Pillar Mechanics and Design. U. S. Bureau of Mines, Washington, DC. pp. 128-143. 
Table 1 Mechanical parameters of the rock

\begin{tabular}{|ll|}
\hline Parameters & Value \\
\hline Poisson's ratio, $v$ & 0.18 \\
Young's modulus, $E(\mathrm{GPa})$ & 30 \\
Cohesion, $c(\mathrm{MPa})$ & 30 \\
Tension cut-off, $\sigma_{\mathrm{t}}(\mathrm{MPa})$ & 7 \\
Friction angle, $\varphi\left({ }^{\circ}\right)$ & 24 \\
Dilation angle, $\psi\left({ }^{\circ}\right)$ & 24 \\
\hline
\end{tabular}

Table 2 Strain-softening parameters of the rock in simulation

\begin{tabular}{|ll|ll|}
\hline Cohesion yield stress (MPa) & Shear plastic strain & Tension cut-off stress (MPa) & Tensile plastic strain \\
\hline 30.0 & 0 & 7.0 & 0 \\
26.7 & 0.020 & 0.1 & 0.009 \\
17.3 & 0.065 & & \\
9.0 & 0.123 & & \\
1.0 & 0.171 & & \\
\hline
\end{tabular}

Table 3 Calibrated thermal parameters for the thermal loading platen used in simulation

\begin{tabular}{|ll|}
\hline Thermal parameters & Value \\
\hline Conductivity at Room Temperature $(\mathrm{RT})\left(\mathrm{W} \cdot \mathrm{m}^{-1} \mathrm{~K}^{-1}\right)$ & 0.15 \\
Expansion coefficient in the vertical direction at $\mathrm{RT}\left(\mathrm{K}^{-1}\right)$ & 0.0007 \\
Specific heat at RT $\left(\mathrm{J} \cdot \mathrm{kg}^{-1} \mathrm{~K}^{-1}\right)$ & 1900 \\
Heat flux $(W)$ & $2.005 \times 10^{10}$ \\
\hline
\end{tabular}

Table 4 Relation between $L S R I$ and $L S S$ together with rock failure types interpreted

\begin{tabular}{|l|l|l|l|l|}
\hline $\operatorname{LSS}(\mathrm{GN} / \mathrm{m})$ & 61 & $24(=\lambda)$ & 19 & 15 \\
\hline LSRI & 1.19 & 2.23 & 3.84 & 8.85 \\
\hline Rock failure type & Stable & Critical & Transition & Unstable \\
\hline
\end{tabular}




\section{Figure Captions}

Figure 1 Schematic of a traditional stiff test machine for observing complete stress-strain curves of rock.

Figure 2 An explanation for the relation between rock creep and delayed rockburst in loaddeformation curve.

Figure 3 Energy transfer in rock specimen-test machine system with the supplement of external input energy.

Figure 4 Energy transfer in rock specimen-test machine system during the rock failure process when $L S S<\lambda$ (loading condition of unstable rock failure).

Figure 5 Energy transfer in rock specimen-test machine system during the rock failure process when $L S S=\lambda$ (critical loading condition of stable rock failure).

Figure 6 Energy transfer in rock specimen-test machine system during the rock failure process when $L S S>\lambda$ (general loading condition of stable rock failure).

Figure 7 Schematic of different rock failure processes under same $L S S>\lambda$ while input energy is drastically different.

Figure 8 Rock specimen under uniaxial compression applied by the ideal loading condition: (a) schematic of the loading condition, and (b) FEM model.

Figure 9 Stress-strain curve of a rock specimen under the ideal loading condition in uniaxial compression.

Figure 10 Rock specimen under uniaxial compression applied by the frame-platen loading condition: (a) schematic of the loading condition, and (b) FEM model.

Figure 11 Displacement-time relations of rock specimens under two loading conditions.

Figure 12 Calibration of frame-platen loading test machine's LSS in numerical modeling.

Figure 13 Calibrated load-displacement relations of the frame-platen loading test machine.

Figure 14 Stress-strain curve of the rock under $L S S=61 \mathrm{GN} / \mathrm{m}$ and the ideal loading condition, along with the accumulative energy $E_{\text {in }}{ }^{*}$ and $E_{\mathrm{t}}{ }^{*}$.

Figure 15 Stress-strain curves of the rock under $L S S=24 \mathrm{GN} / \mathrm{m}$ and the ideal loading condition, along with the accumulative energy $E_{\text {in }}{ }^{*}$ and $E_{\mathrm{t}}{ }^{*}$.

Figure 16 Stress-strain curve of the rock under $L S S=19 \mathrm{GN} / \mathrm{m}$ and the ideal loading condition, along with the accumulative energy $E_{\text {in }}{ }^{*}$ and $E_{\mathrm{t}}{ }^{*}$. 
Figure 17 Stress-strain curves of the rock under $L S S=15 \mathrm{GN} / \mathrm{m}$ and the ideal loading condition, along with the accumulative energy $E_{\text {in }}{ }^{*}$ and $E_{\mathrm{t}}{ }^{*}$.

Figure 18 Calculation of LSRI (after Manouchehrian and Cai 2015).

Figure 19 Relation between reaction velocity and time for the rock under $L S S=19 \mathrm{GN} / \mathrm{m}$ in the post-peak deformation stage.

Figure 20 Explanation for the oscillatory reaction velocity in the post-peak deformation stage. 


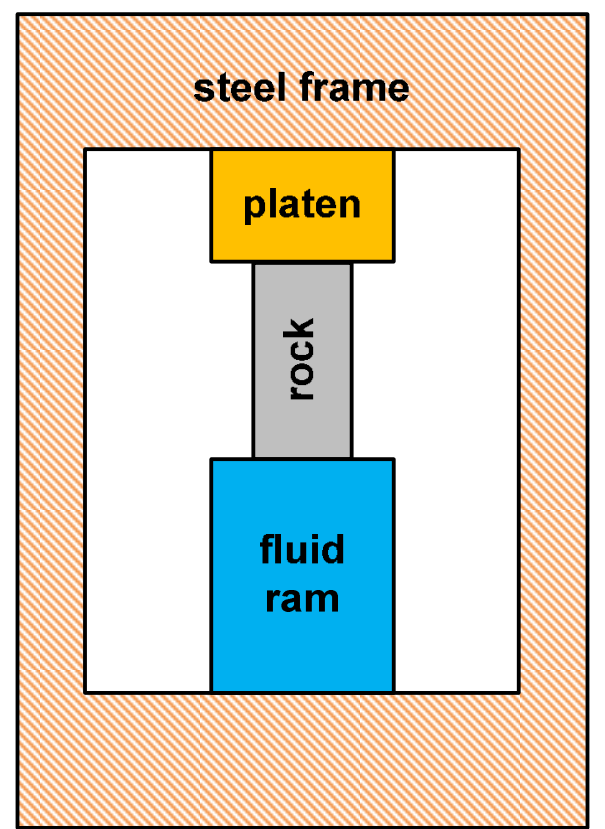

Figure 1 Schematic of a traditional stiff test machine for observing complete stress-strain curves of rock.

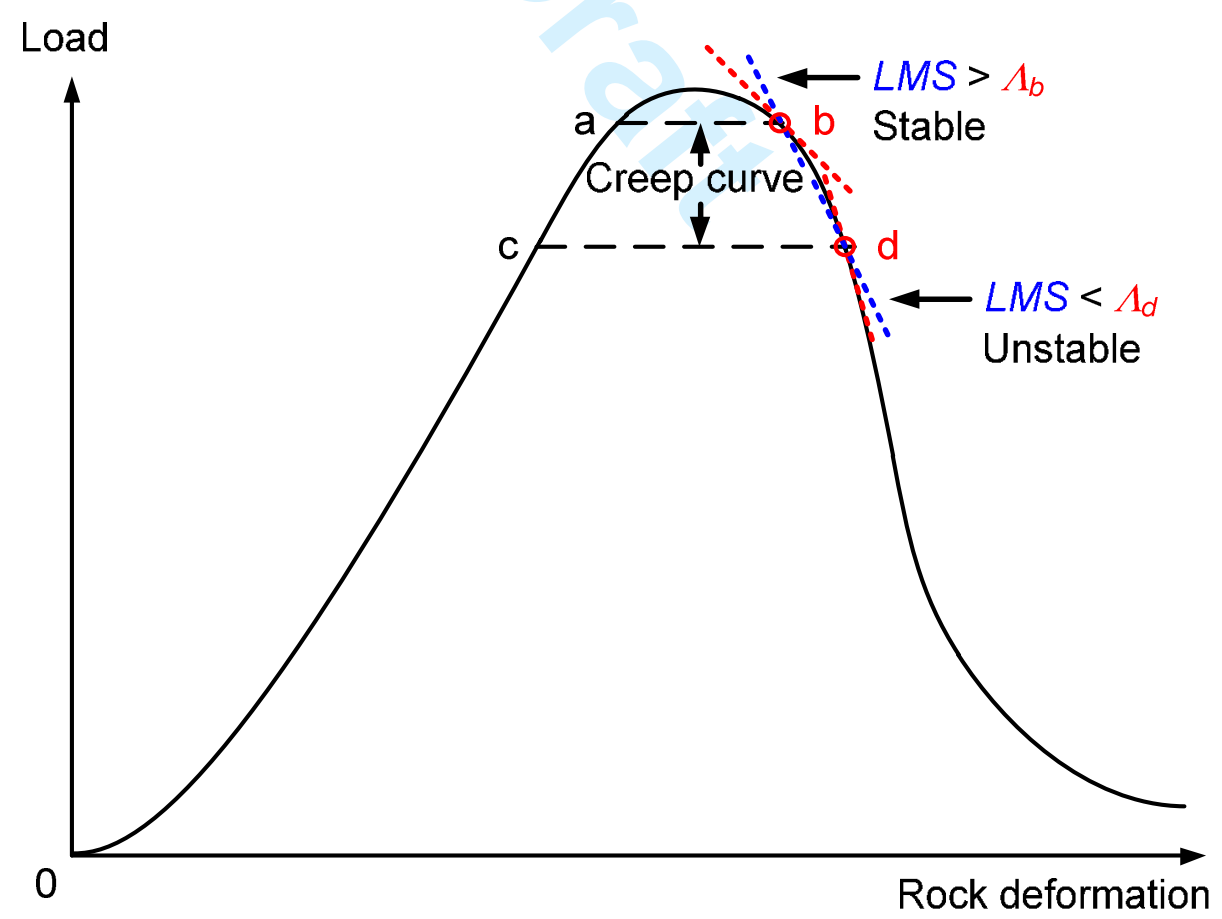

Figure 2 An explanation for the relation between rock creep and delayed rockburst in load-deformation curve. 


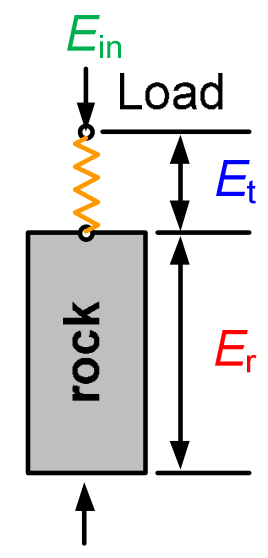

Figure 3 Energy transfer in rock specimen-test machine system with the supplement of external input energy.
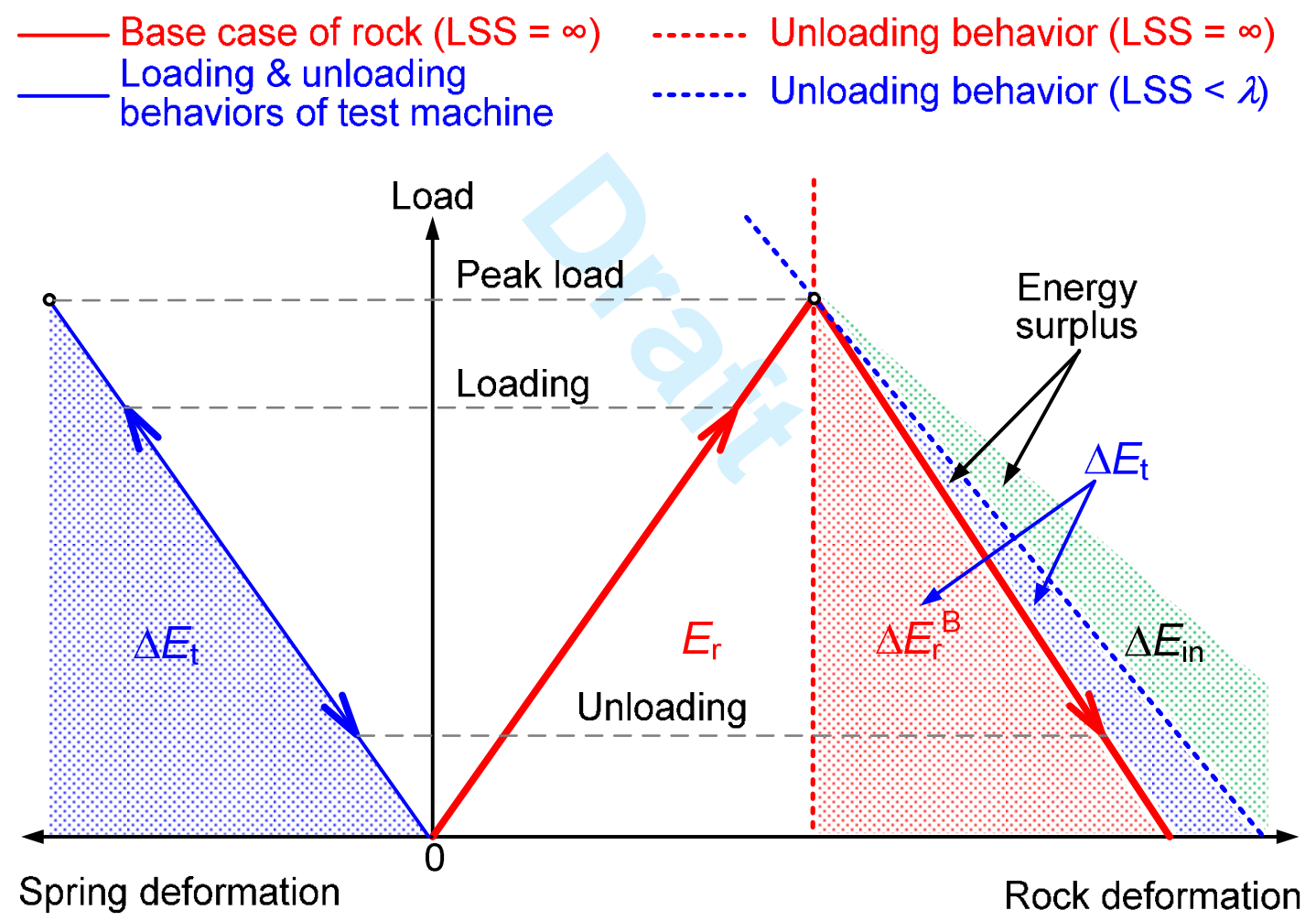

Figure 4 Energy transfer in rock specimen-test machine system during the rock failure process when $L S S<\lambda$ (loading condition of unstable rock failure). 


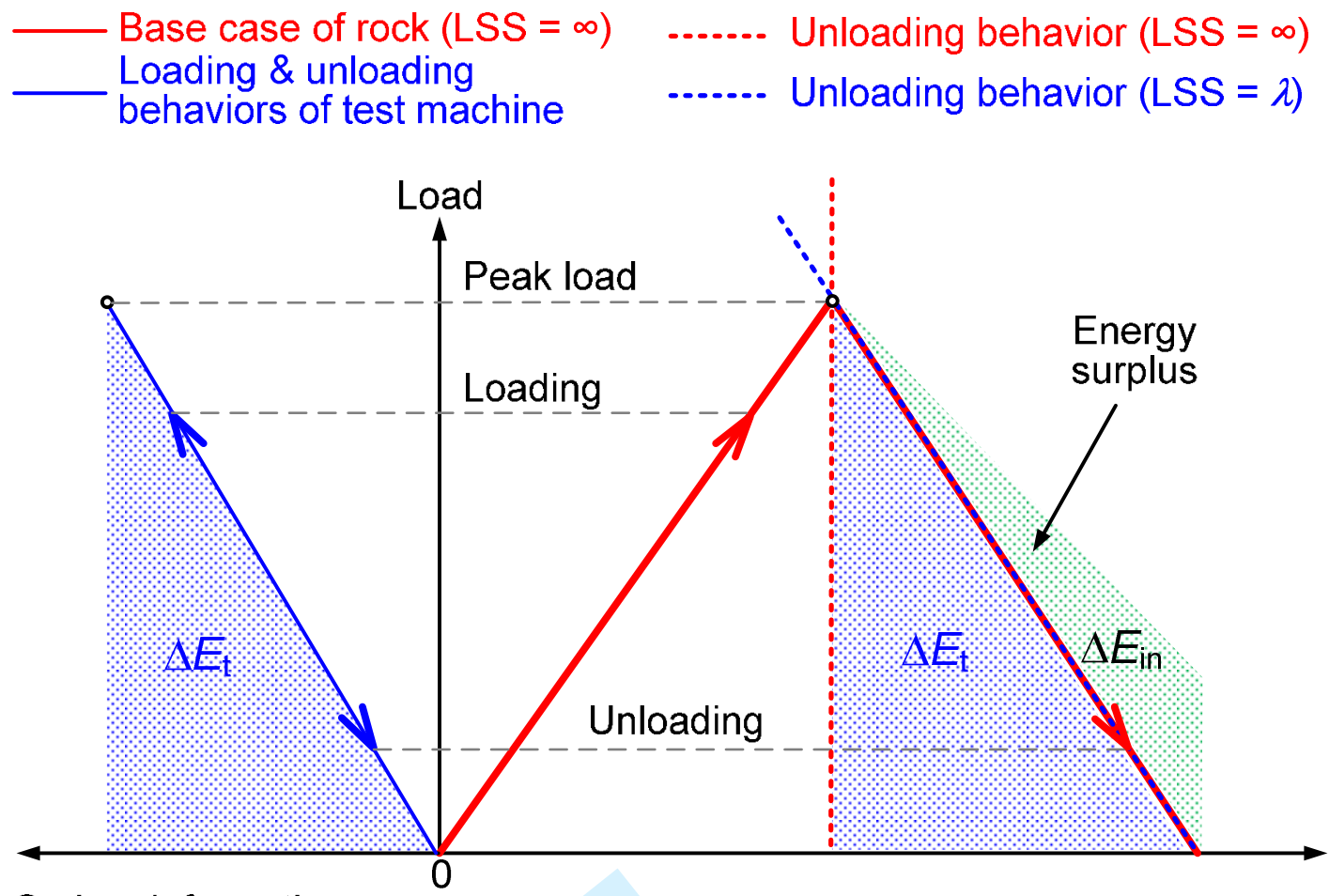

Spring deformation

Rock deformation

Figure 5 Energy transfer in rock specimen-test machine system during the rock failure process when $L S S=\lambda$ (critical loading condition of stable rock failure).

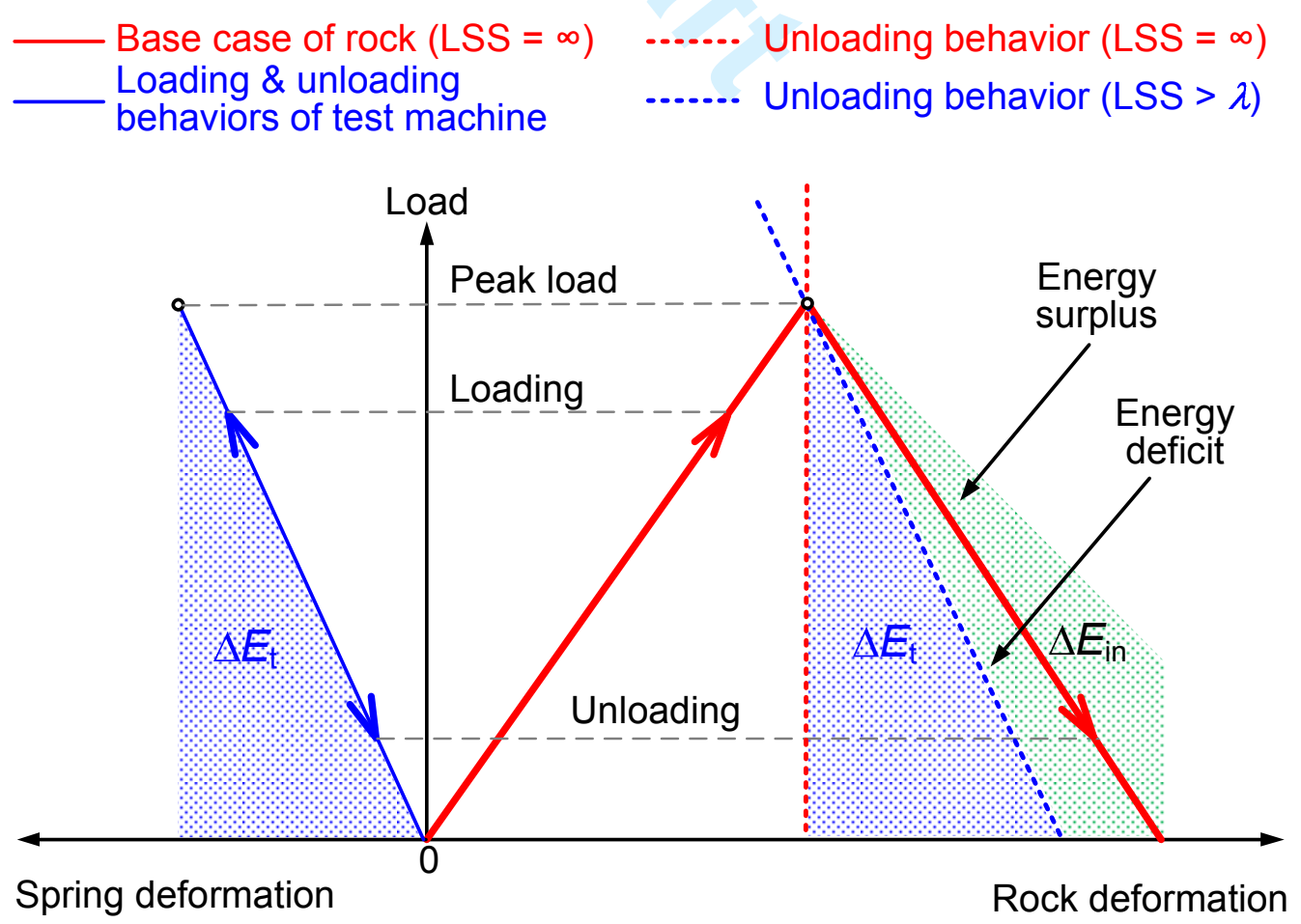

Figure 6 Energy transfer in rock specimen-test machine system during the rock failure process when $L S S>\lambda$ (general loading condition of stable rock failure). 
Figure 7 Schematic of different rock failure processes under same $L S S>\lambda$ while input energy is drastically different.

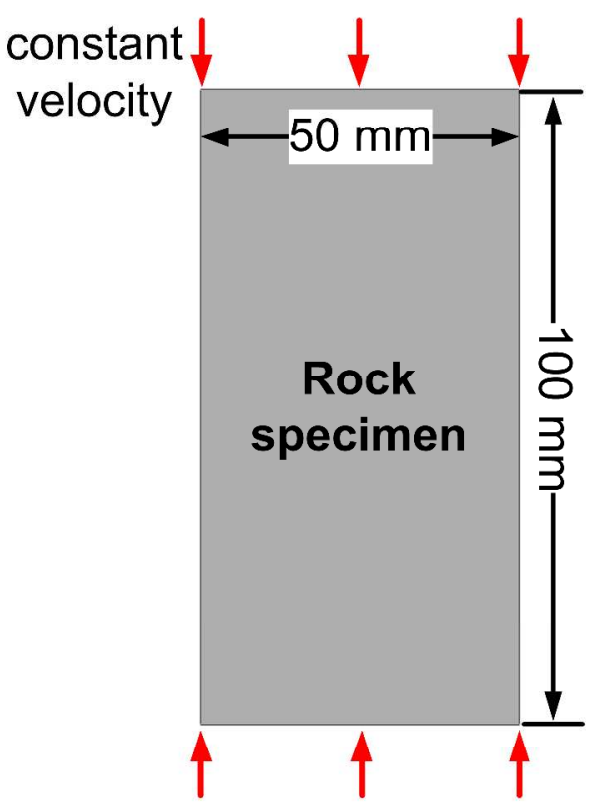

(a)

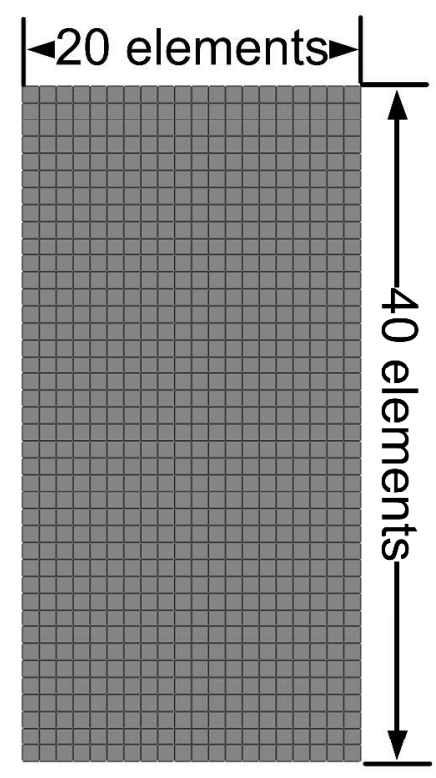

(b)

Figure 8 Rock specimen under uniaxial compression applied by the ideal loading condition:

(a) schematic of the loading condition, and (b) FEM model. 


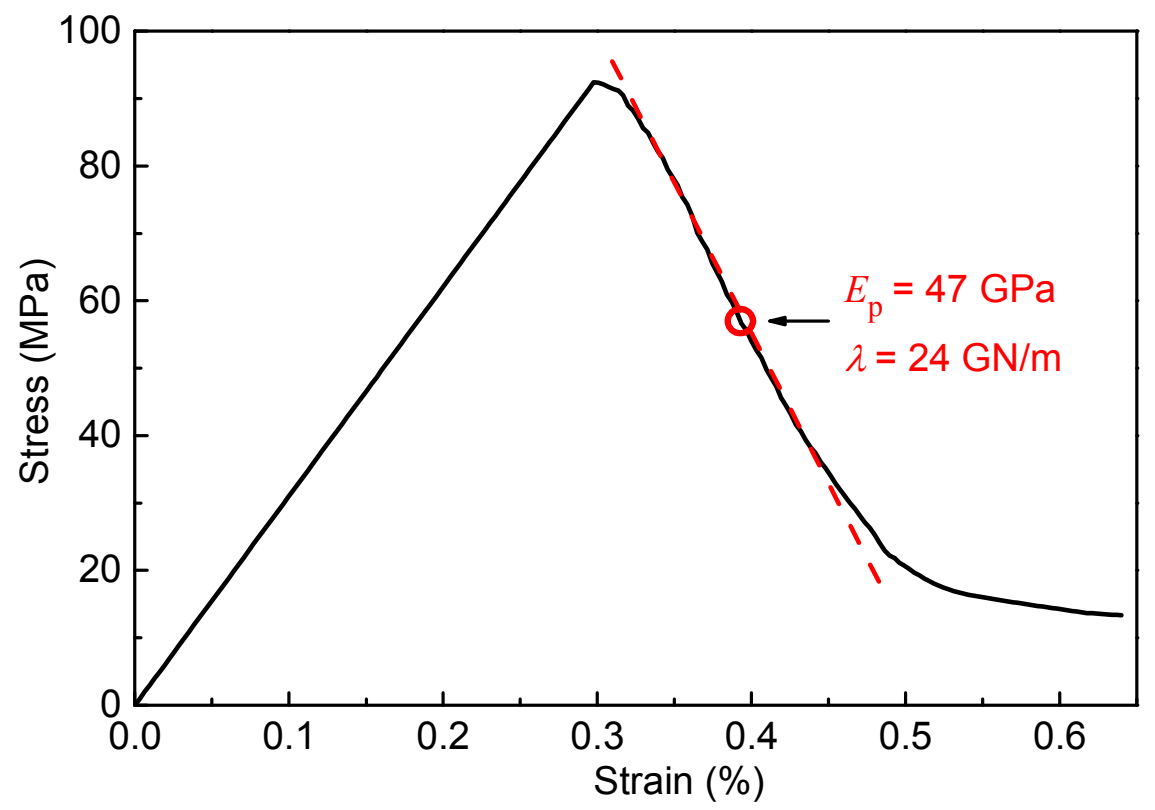

Figure 9 Stress-strain curve of a rock specimen under the ideal loading condition in uniaxial compression.

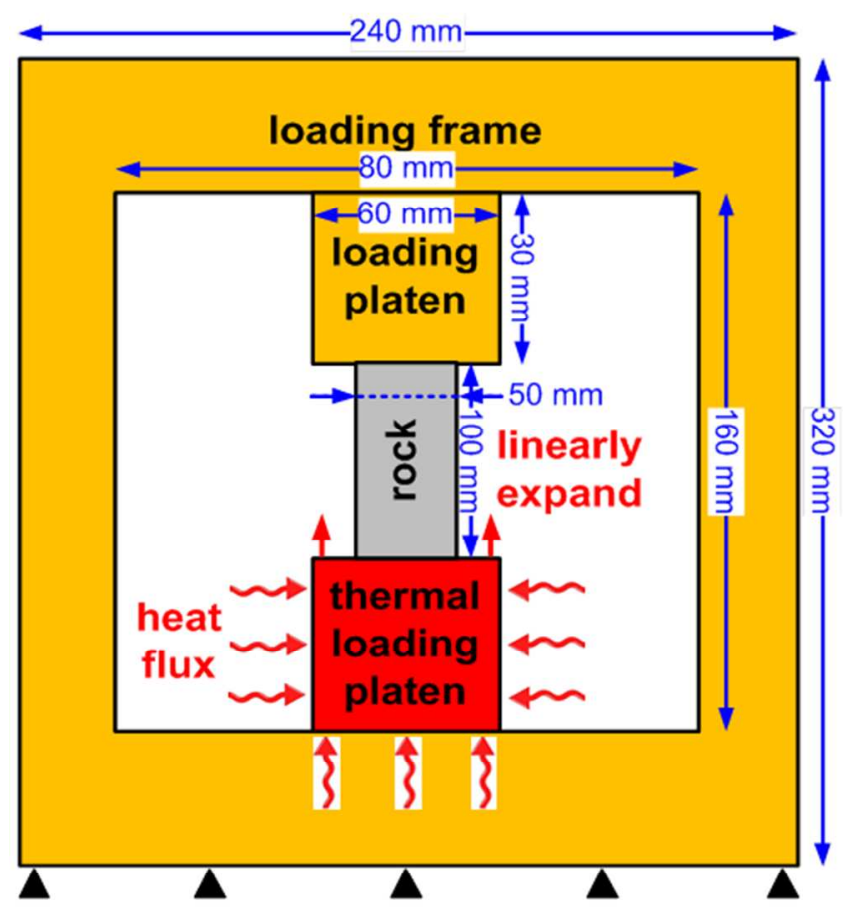

(a)

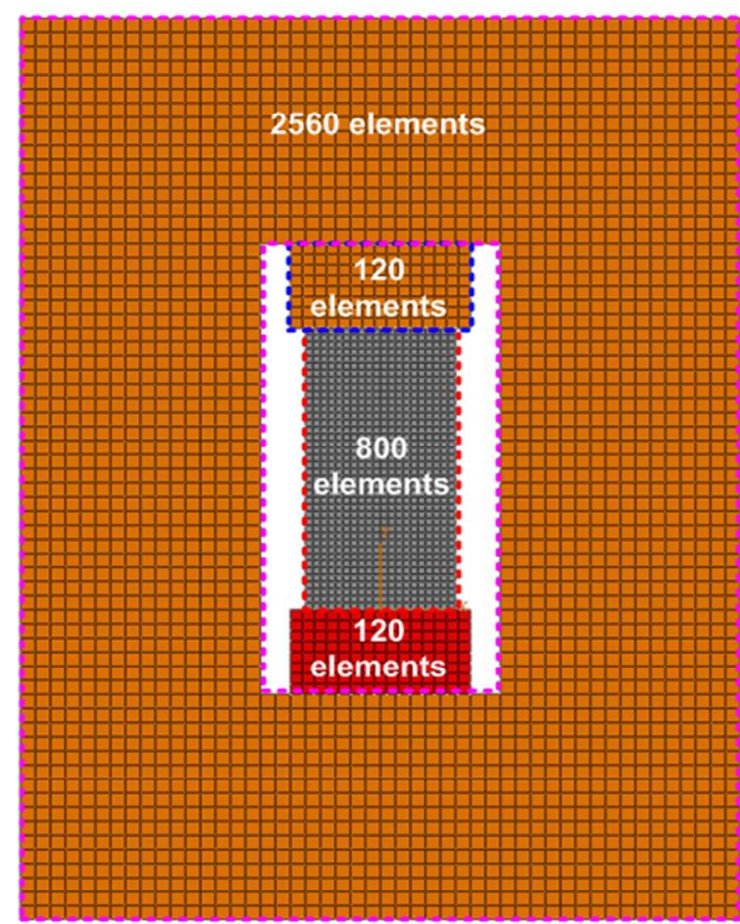

(b)

Figure 10 Rock specimen under uniaxial compression applied by the frame-platen loading condition: (a) schematic of the loading condition, and (b) FEM model. 


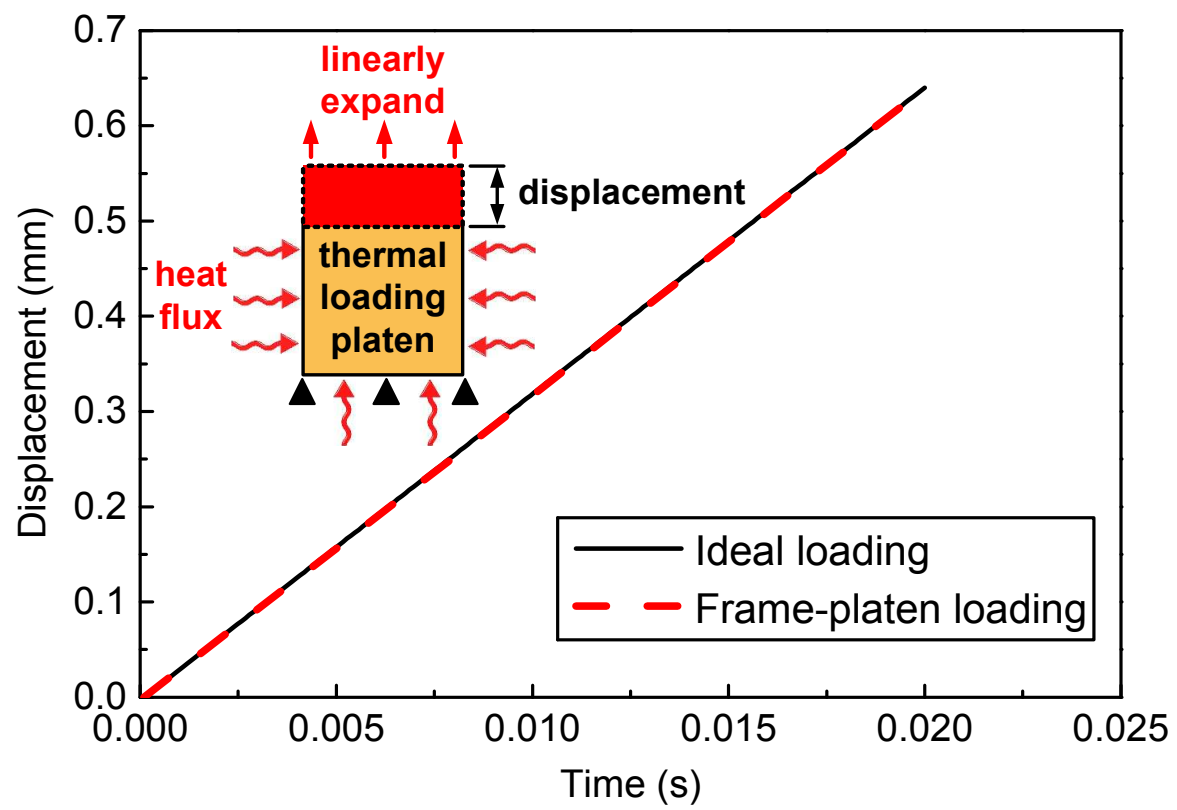

Figure 11 Displacement-time relations of rock specimens under two loading conditions.

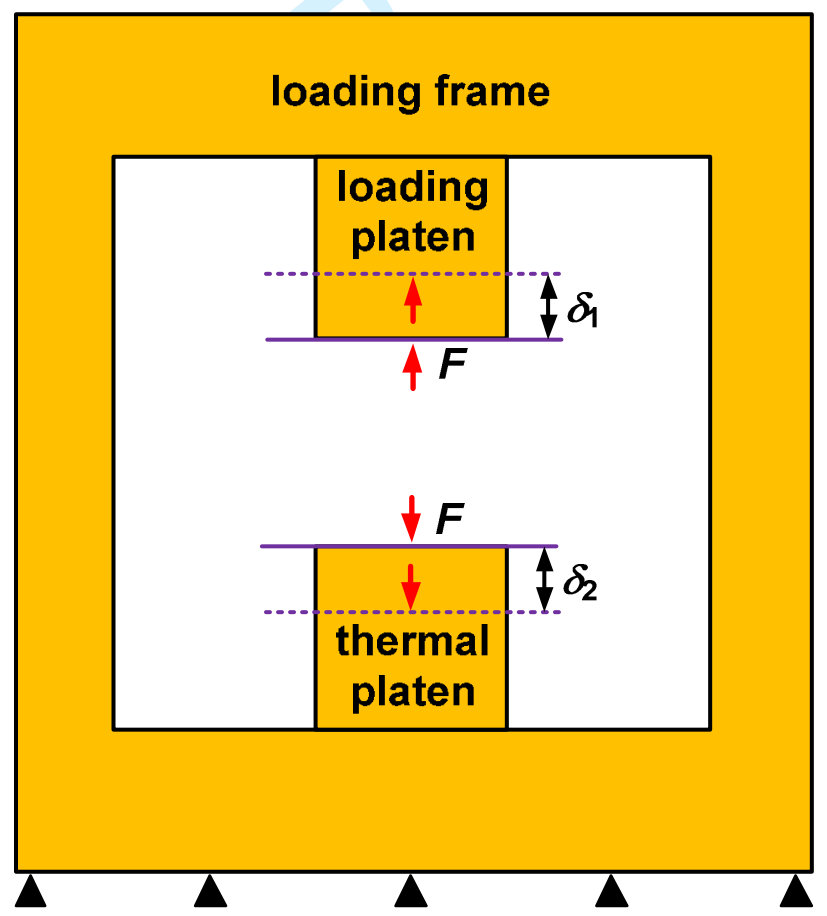

Figure 12 Calibration of frame-platen loading test machine's $L S S$ in numerical modeling. 


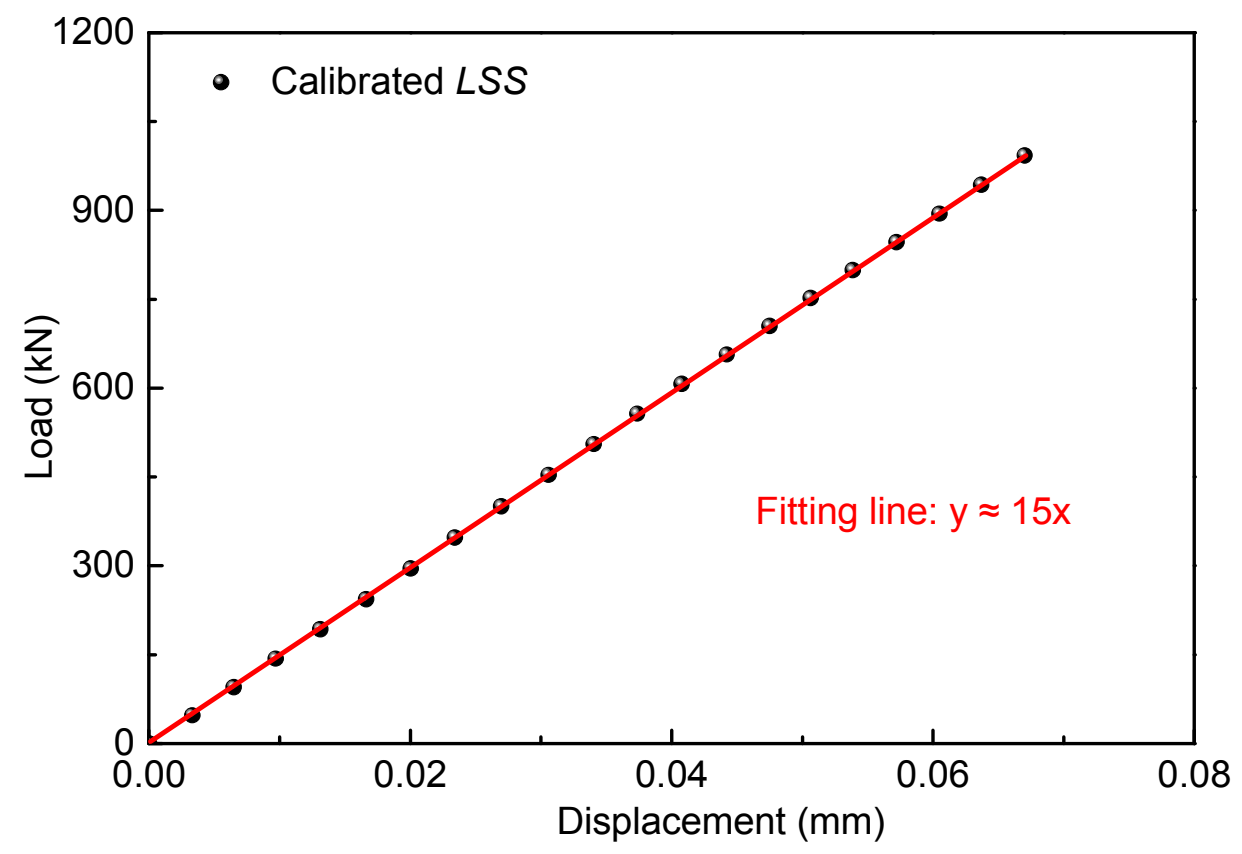

Figure 13 Calibrated load-displacement relations of the frame-platen loading test machine.

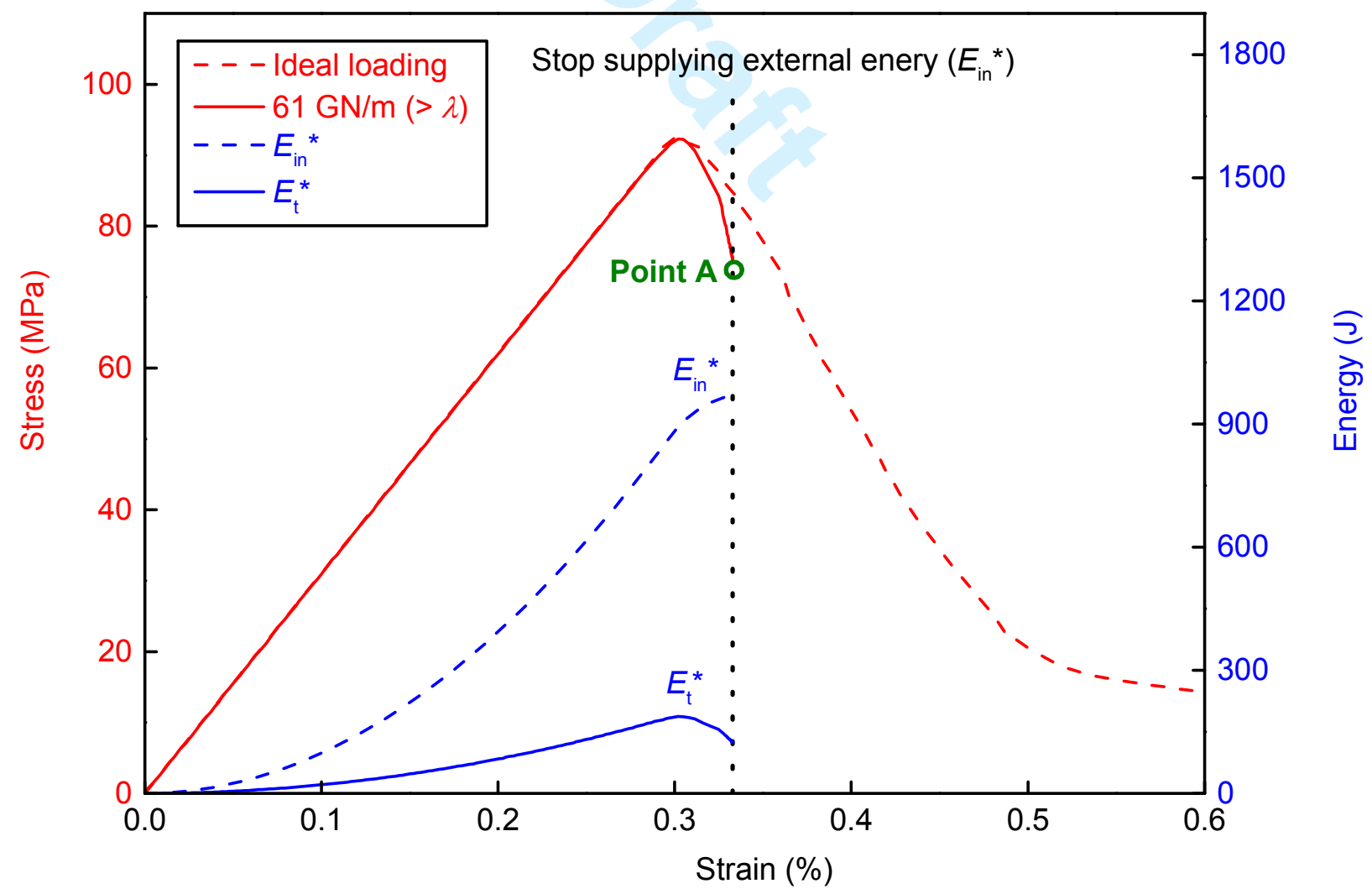

Figure 14 Stress-strain curve of the rock under $L S S=61 \mathrm{GN} / \mathrm{m}$ and the ideal loading condition, along with the accumulative energy $E_{\mathrm{in}}{ }^{*}$ and $E_{\mathrm{t}}{ }^{*}$. 


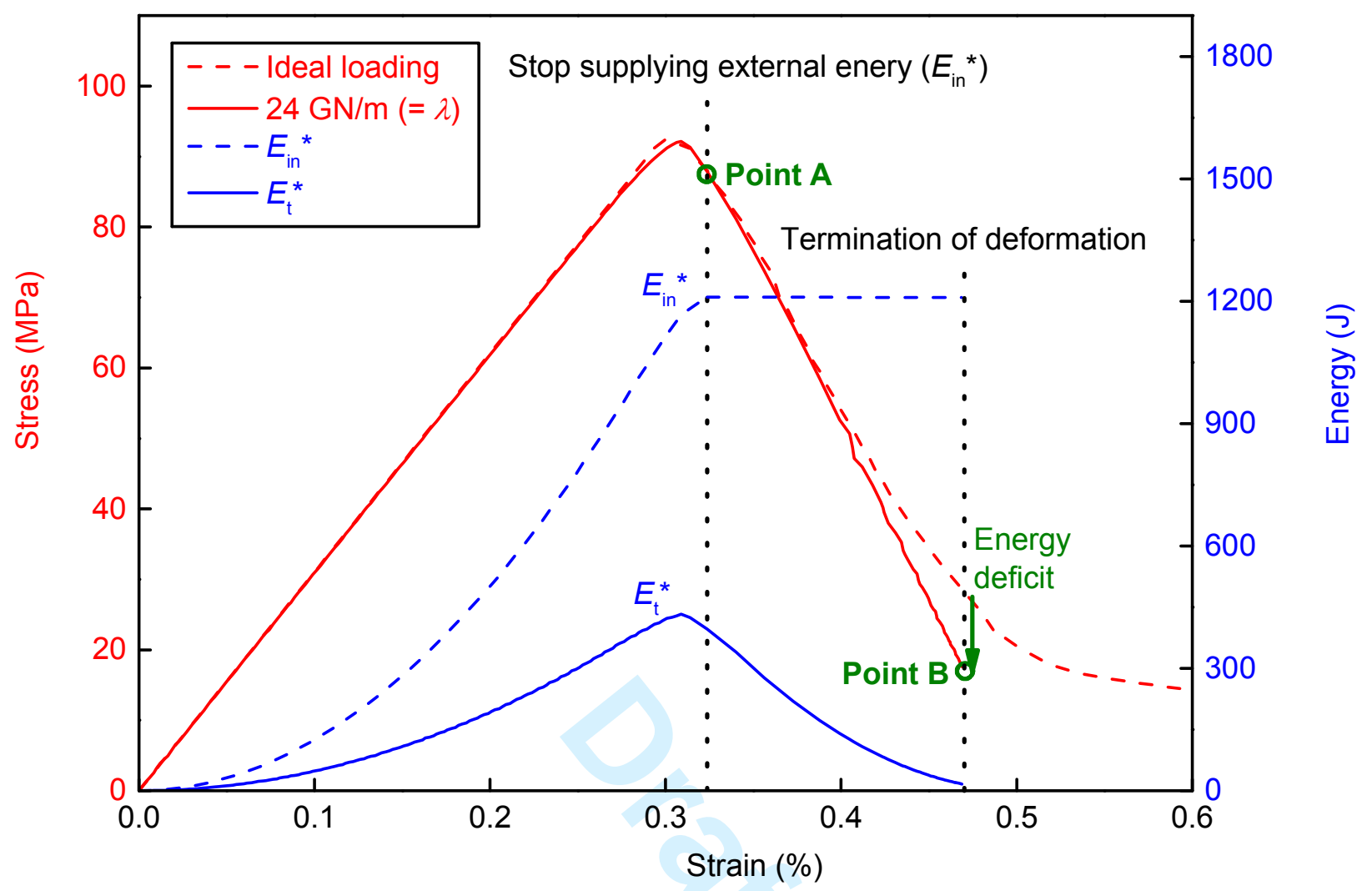

Figure 15 Stress-strain curves of the rock under $L S S=24 \mathrm{GN} / \mathrm{m}$ and the ideal loading condition, along with the accumulative energy $E_{\text {in }}{ }^{*}$ and $E_{\mathrm{t}}{ }^{*}$. 


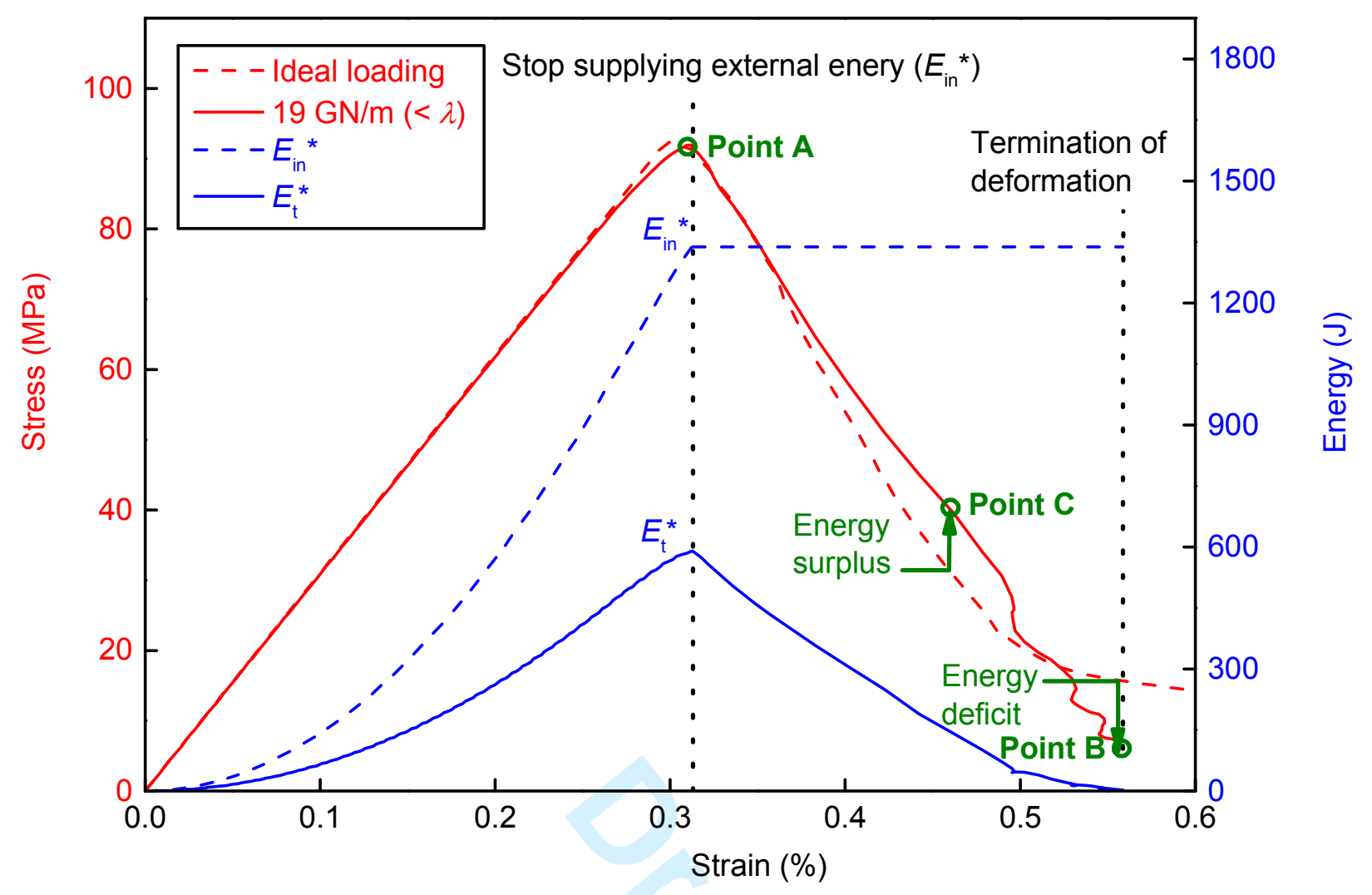

Figure 16 Stress-strain curve of the rock under $L S S=19$ GN/m and the ideal loading condition, along with the accumulative energy $E_{\text {in }}{ }^{*}$ and $E_{\mathrm{t}}{ }^{*}$. 


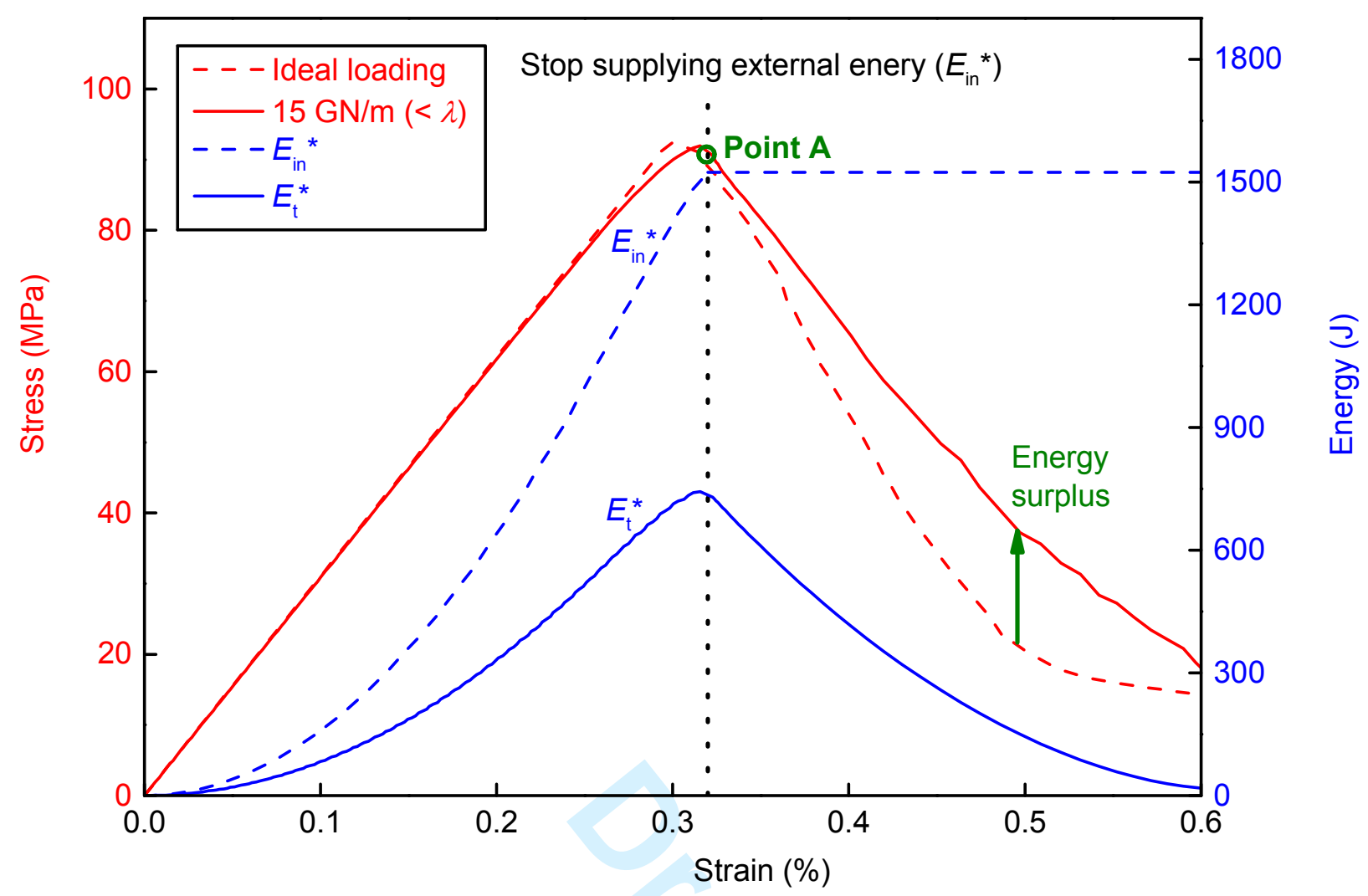

Figure 17 Stress-strain curves of the rock under $L S S=15 \mathrm{GN} / \mathrm{m}$ and the ideal loading condition, along with the accumulative energy $E_{\mathrm{in}}{ }^{*}$ and $E_{\mathrm{t}}{ }^{*}$.

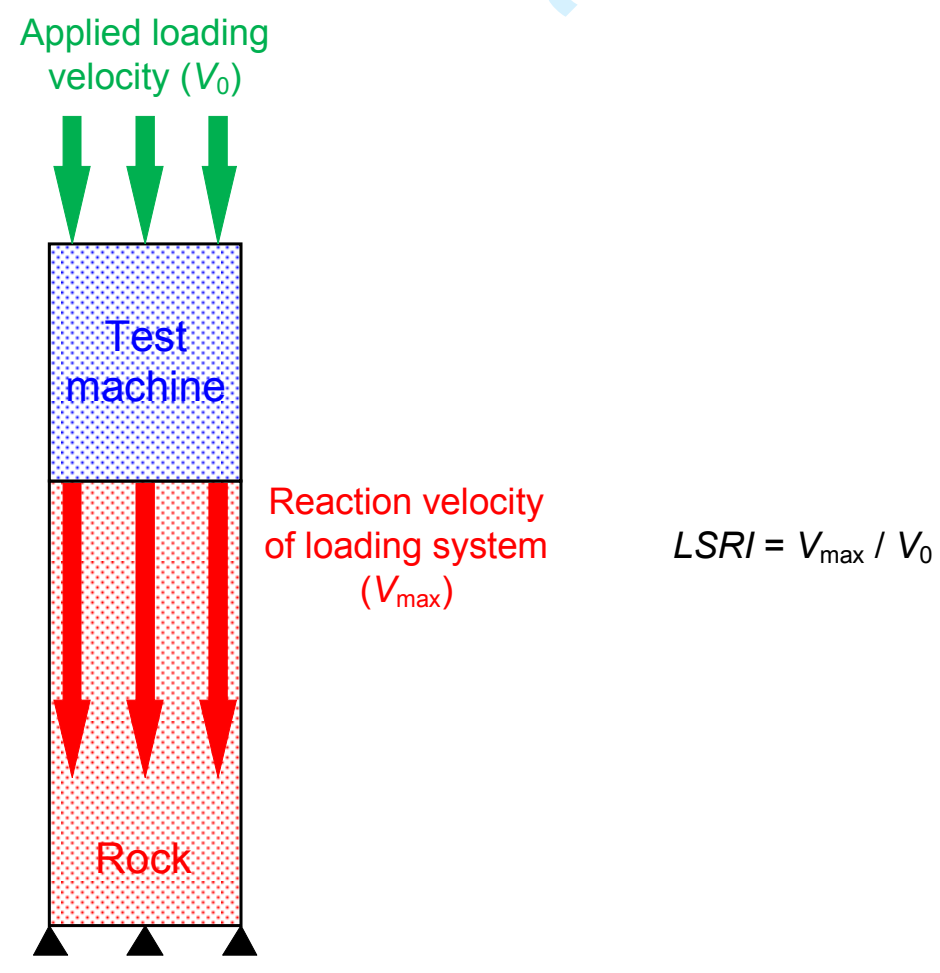


Figure 18 Calculation of LSRI (after Manouchehrian and Cai 2015).

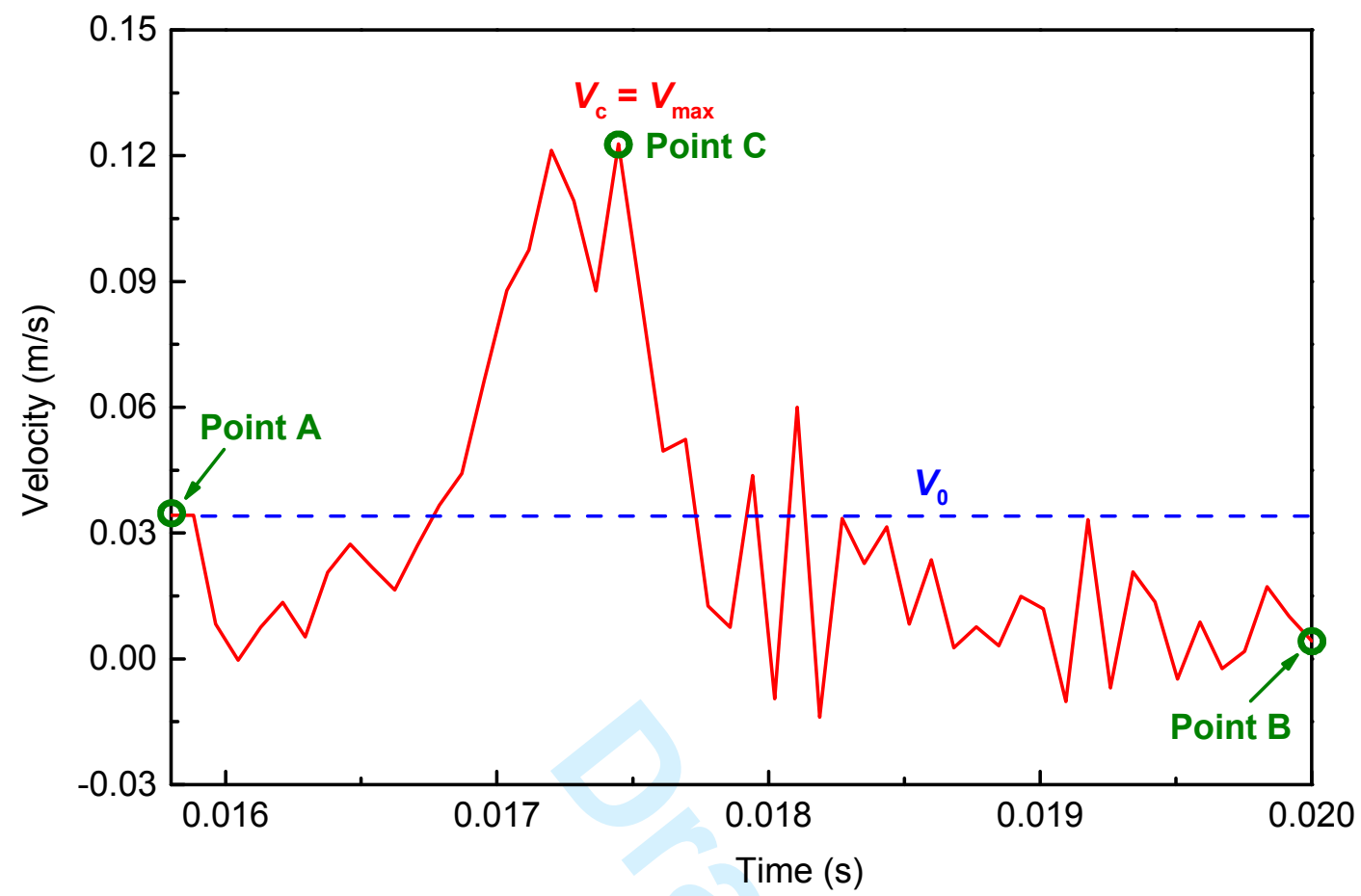

Figure 19 Relation between reaction velocity and time for the rock under $L S S=19 \mathrm{GN} / \mathrm{m}$ in the post-peak deformation stage.

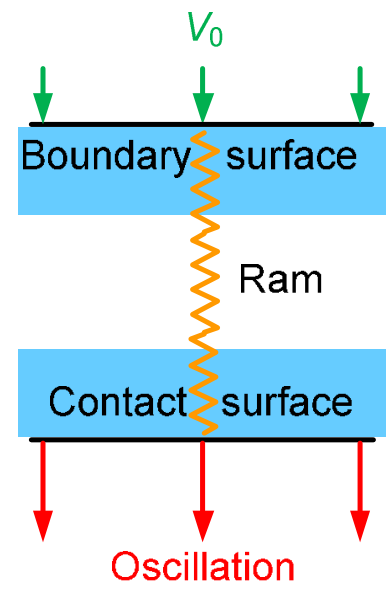

\section{Specimen end}

Figure 20 Explanation for the oscillatory reaction velocity in the post-peak deformation stage. 